DOCUMENTA

\title{
HOMENAGEM A GILBERTO VELHO
}

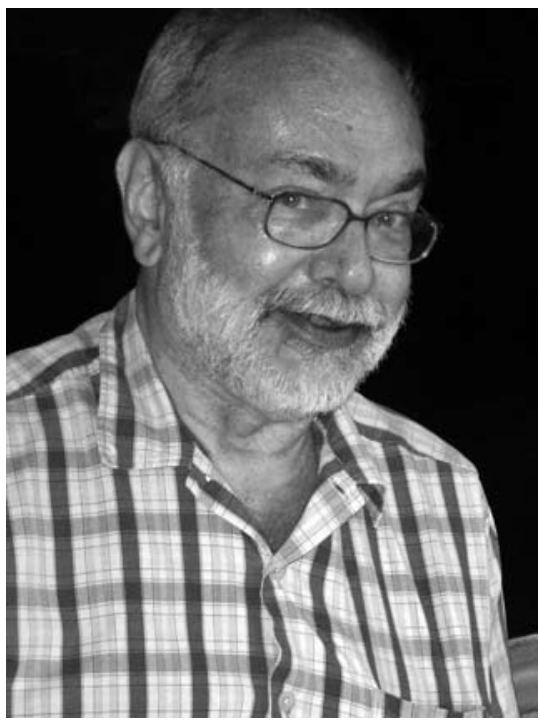





\section{NOTA DOS EDITORES}

Este memorial foi apresentado por Gilberto Velho em 1992 para o concurso de Professor Titular de Antropologia Social do Museu Nacional. É um texto que traz a autoapresentação de sua trajetória para uma banca de concurso. Aos 47 anos, Gilberto escreveu este memorial numa data equidistante do começo e do fim de sua vida profissional. Vinte anos antes ele voltava de um estágio pré-doutoral nos Estados Unidos, em 1972, e era publicada naquele mesmo ano a primeira edição de A Utopia Urbana, sua dissertação de mestrado. Vinte anos depois de seu concurso para titular, sua carreira, já como decano do Museu Nacional, era interrompida em plena atividade.

Até então o único titular vinculado ao PPGAS-MN era o professor Luiz de Castro Faria, professor emérito desde 1983 e decano do Departamento de Antropologia do Museu Nacional. Roberto Cardoso de Oliveira, fundador do PPGAS em 1968, com o apoio de Castro Faria, pouco tempo após fazê-lo foi preterido na sua pretensão à titularidade devido à manipulação de critérios por parte das autoridades universitárias de então, beneficiando o tempo de serviço em detrimento da produção científica. Por causa disso, saiu do $\mathrm{Mu}$ seu Nacional e da UFRJ em 1973 para colaborar na fundação do PPGAS da UnB, onde haviam se estabelecido alguns de seus antigos discípulos. Roberto DaMatta, coordenador depois de Roberto Cardoso no PPGAS-MN na década de 1970, desistiu de esperar que uma vaga de titular resistisse à escassez, à seletividade distributiva da UFRJ e à alocação dentro do Museu, e aceitou convite da universidade estadunidense Notre Dame no final da década seguinte. Assim, no início dos anos 1990, o déficit de titulares no PPGAS-MN era grande. As primeiras duas vagas que contemplaram o PPGAS foram preenchidas por Otávio Velho e Gilberto Velho através do concurso de $1992{ }^{1}$ As conferências de ambos foram publicadas conjuntamente. ${ }^{2}$

Um ano antes de seu falecimento, Gilberto publicou uma reflexão sobre sua carreira em abril de 2011, nesta revista, "Antropologia Urbana: Interdisciplinaridade e Fronteiras do Conhecimento" (Mana, 17(1):161-185), na qual discorreu com maior desenvoltura sobre as indicações iniciadas no memorial. ${ }^{3}$

No entanto, o memorial apresentado em 1992 traz para nós o frescor de um documento que retrata um trabalho em andamento. ${ }^{4} \mathrm{O}$ texto original, depositado para consulta pública na biblioteca Francisca Keller do PPGAS-MN, 
tinha a preocupação de responder ao que era solicitado no edital do concurso e visava guiar a banca no exame da vasta documentação que o complementava em anexo. O plano do texto denotava em suas partes e subpartes a intenção de acompanhar mais de perto as seções principais de um vasto curriculum vitae. ${ }^{5}$ Por outro lado, na presente edição do memorial foram eliminadas as referências numéricas diretas aos itens do CV e da documentação comprobatória. Quando pertinentes, foram feitas, em notas de fim, indicações de publicações evocadas no texto.

Complementando o texto original, foram produzidos anexos com a relação de publicações e de orientandos até 2012, de forma que as citações que faziam parte do campo de possibilidades do autor em 1992 fossem cotejadas com a relação completa do balanço de sua carreira.

Até a época do concurso, Gilberto Velho já tinha construído o essencial das características de sua trajetória específica. Além das pesquisas e dos textos referentes ao seu mestrado e ao seu doutorado, ele já havia estruturado a área singular de uma antropologia urbana brasileira, tinha consolidado seus grupos de alunos, pesquisadores e seguidores, sua coleção editorial na Antropologia Social em uma grande editora nacional, seus correspondentes internacionais e parte de sua rede social de construção institucional. Já havia sido presidente da ABA entre 1982 e 1984, bem como vice-presidente da SBPC em 1991 e 1992 (no momento mesmo do concurso). Também participara dos processos de avaliação tanto da pós-graduação em Ciências Humanas da CAPES e do CNPq, quanto da pesquisa científica nacional envolvendo os setores de planejamento do governo federal associados à SBPC e à Academia Brasileira de Ciências. Já havia sido membro do Conselho Deliberativo do $\mathrm{CNPq}$, eleito pela comunidade acadêmica. E fizera parte de Conselhos de Patrimônio e Cultura dos governos federal e estadual.

Depois do período contemplado neste memorial, suas atividades ampliaram-se, tendo se tornado presidente da ANPOCS logo em seguida (entre 1994 e 1996), jurado dos editais de programas nacionais de excelência científica (PRONEX) e integrado o primeiro grupo das Ciências Sociais a ingressar, por eleição de seus membros, na Academia Brasileira de Ciências. Também foi depois do memorial que chegou a publicar, em 1998, sua tese de doutorado, Nobres e Anjos, cujas temática e informações pontuais poderiam trazer consequências repressivas ou persecutórias para os pesquisados durante a ditadura (sua tese é de 1975, dez anos antes do término formal daquele regime). Tal lapso de tempo também respeitava o transcurso de um período de distanciamento dos fatos relatados que pudessem ferir susceptibilidades dos pesquisados anônimos, mas de possível identificação. Mas aquela experiência já havia lhe servido de suporte para reflexões im- 
portantes sobre a pesquisa antropológica acerca do familiar e do próximo, uma precoce "anthropology at home" servindo de contraponto à pesquisa sobre o outro. E que produziu uma linha de pesquisa frutífera, iluminando os caminhos de muitos orientandos e jovens pesquisadores. Apoiou ainda teses e dissertações pioneiras sobre objetos distantes daqueles sobre os quais havia se debruçado diretamente, desde estilos e gêneros musicais até sexualidade, passando pela formação militar, pela militância pelo folclore nacional, pela política suburbana e pelo estudo do primeiro sindicato de jogadores de futebol, entre outros temas.

Também o seu papel de decano exercido no PPGAS, no Departamento de Antropologia e no Museu Nacional, após a aposentadoria do professor Castro Faria, representou uma prática de sabedoria social adquirida pela idade e pela experiência vivida. Então, a eventual emulação agonística havida entre as primeiras gerações dos professores do PPGAS, com suas respectivas linhas inovadoras e posicionalmente diferenciadas em construção, da qual Gilberto Velho foi ativo partícipe, deu lugar a uma valorização da tolerância e dos méritos de uma elaboração científica e institucional diversificada e plural. Sua parte nessa construção já tinha suas bases de sustentação retratadas neste memorial de 1992. Com este texto de trabalho em andamento, de work in progress, prestamos uma homenagem à memória de nosso colega Gilberto Velho.

\section{Notas}

${ }^{1}$ Posteriormente foi a vez de Moacir Palmeira (em 1994) e de João Pacheco de Oliveira (1997). Depois de outro grande intervalo, os seguintes foram Eduardo Viveiros de Castro e José Sergio Leite Lopes (em 2011).

${ }^{2}$ Gilberto Velho e Otávio Guilherme Velho. Duas Conferências. 1992. Rio de Janeiro: Editora da UFRJ. 86pp.

${ }^{3}$ O caráter de evocação reflexiva de uma trajetória, que caracteriza o gênero "memorial", está presente naquele artigo de abril de 2011. "Nesta etapa avançada de minha carreira [...] [ao] apresentar reflexões em torno do que entendo sobre o trabalho antropológico classificado como Antropologia Urbana, [...] não posso deixar de sublinhar uma singularidade inseparável de aspectos pessoais".

${ }^{4}$ Cf. o parágrafo final do texto do memorial a seguir. 
${ }^{5} \mathrm{O}$ sumário que precedia o texto foi eliminado para aliviar a publicação na revista. As subdivisões que estavam na folha de sumário estão no texto, pontuando suas subpartes. O texto se divide assim em três partes: 1. "formação e títulos acadêmicos" (subdividido em "antecedentes", "graduação" e "pós-graduação"); 2. "realizações profissionais" ("áreas de pesquisa científica, produção intelectual e publicações", por um lado, e "atividades docentes", por outro); e finalmente 3. "atividades complementares - cargos acadêmicos, administrativos, política científica e cultural". 


\section{MEMORIAL}

\section{Gilberto Cardoso Alves Velho}

Memorial para o Concurso de Professor Titular de Antropologia Social, Departamento de Antropologia do Museu Nacional, Universidade Federal do Rio de Janeiro

Apresentado pelo candidato

Gilberto Cardoso Alves Velho

Nascido no Rio de Janeiro, em 15 de maio de 1945, filho de Octávio Alves Velho e de Dulce Cardoso Alves Velho

\section{Formação e títulos acadêmicos}

\section{I.1 Antecedentes}

Foi essencial na minha formação, desde cedo, o apoio e o ambiente intelectual familiares. A existência de uma boa biblioteca e o estímulo constante foram fundamentais para toda a minha carreira. Depois de concluir o então curso primário, ingressei no Colégio de Aplicação da antiga Faculdade Nacional de Filosofia da Universidade do Brasil (hoje CAP da Faculdade de Educação da Universidade Federal do Rio de Janeiro).

O curso secundário foi extremamente importante, graças à excelente qualidade do ensino então ministrado naquele colégio-modelo. Fui particularmente estimulado pelos professores de História e Geografia, entre os quais destaco: Lidynéa Gassman, Hugo Weiss, Mauricio Silva Santos, Clovis Dottori e José Luiz Werneck da Silva. Alguns destes voltei a encontrar na Universidade em outros momentos de minha vida profissional.

Assim, a minha formação inicial em Ciências Humanas é produto do ambiente familiar e de um excepcional curso secundário. Não posso deixar de registrar que o curso de Estudos Sociais que fiz no clássico do Colégio de Aplicação, com os professores Werneck e Silva Santos foi de nível comparável aos melhores que fiz na faculdade.

Nesse período do curso clássico, participei de diversos grupos de estudo, nos quais, através de meu irmão Otávio Guilherme, tive contato com alunos 
e professores da Escola de Sociologia e Política da Pontifícia Universidade Católica do Rio de Janeiro (PUC-RJ), na época, provavelmente um dos melhores cursos da área no Brasil. Frequentei também o Instituto Superior de Estudos Brasileiros (ISEB), até seu fechamento. Entre os professores que conheci vale registrar os nomes de Nelson Werneck Sodré, José Guilherme Merquior e Alvaro Vieira Pinto. Durante cerca de dois anos ali assisti a cursos e conferências. Na época, os meus principais interesses intelectuais eram História e Sociologia da Arte que se constituíram no ponto de partida para minha futura profissionalização em Ciências Sociais.

\section{I.2 Curso de Ciências Sociais na Faculdade Nacional de Filosofia/ Instituto de Filosofia e Ciências Sociais da UFRJ, 1965 a 1968}

Entrei na faculdade num período tumultuado depois do afastamento de vários professores e do fechamento do Diretório Acadêmico, após o golpe de 1964. Em 1968, quando estava no último ano, outros docentes foram cassados, por ocasião do Ato Institucional n. 5. Portanto, foi uma época agitada, tensa, mas também de grande atividade política e intelectual. Entre os professores que marcaram positivamente a minha passagem, cito: Stella Maria Faria de Amorim, Rosélia Perissé, Moema Toscano, Francisco Falcón, Manuel Maurício de Albuquerque e, mais uma vez, José Luiz Werneck da Silva. Quero valorizar positivamente dois professores. Evaristo de Moraes Filho foi professor de Sociologia de minha turma num momento particularmente difícil de nossa vida universitária. Sua erudição, competência e entusiasmo eram as mesmas que vim a reencontrar, recentemente, como seu colega no Conselho Federal de Cultura. Marina São Paulo Vasconcellos, professora de Antropologia e depois Diretora do Instituto de Filosofia e Ciências Sociais, desde o meu ingresso na Faculdade apoiou-me e incentivou-me. Tive o privilégio de ser convidado por ela para ingressar na carreira docente como auxiliar de ensino de Antropologia. Punida com a aposentadoria, veio a falecer prematuramente no início dos anos 70.

Em 1966, como aluno do curso de Ciências Sociais, fui convidado pela professora Stella Amorim para trabalhar como auxiliar de pesquisa no antigo Instituto de Ciências Sociais da Universidade do Brasil. Esta instituição de pesquisa viria a se fundir, em 1968, com o curso de Ciências Sociais da antiga FNFI, constituindo, hoje, o Instituto de Filosofia e Ciências Sociais da Universidade Federal do Rio de Janeiro. Trabalhei cerca de dois anos em pesquisas coordenadas pelos professores Maurício Vinhas de Queiroz, Luciano Martins e a própria professora Stella. As pesquisas relacionavam- 
se com temas como "Grandes Grupos Econômicos no Brasil", "Burocracia e Desenvolvimento no Brasil". ${ }^{1}$ Lidei basicamente com o mundo das elites: empresarial, militar e do funcionalismo civil em geral. Durante esse período, convivi com o professor Evaristo de Moraes Filho, diretor do Instituto de Ciências Sociais e conheci profissionais que viriam a ter importância decisiva na minha carreira, como os professores Roberto Cardoso de Oliveira e Luiz de Castro Faria. Além de trabalhar em arquivos e realizar pesquisas bibliográficas, entrevistei e fiz histórias de vida de pessoas dos universos investigados. Alguns dos profissionais com quem trabalhei tinham formação ou forte interesse por Antropologia Social, como os professores Stella Amorim e Maurício Vinhas de Queiroz. A minha passagem pelo ICS foi uma significativa complementação e reforço para a minha formação na faculdade.

\section{I.3 Pós-graduação}

Enquanto lecionava no Instituto de Filosofia e Ciências Sociais (IFCS), entrei como aluno no Programa de Pós-Graduação em Antropologia Social (PPGAS) do Departamento de Antropologia do Museu Nacional/Universidade Federal do Rio de Janeiro, no $2^{\circ}$ semestre de 1969. Concluí os cursos e a dissertação de mestrado A Utopia Urbana: Um Estudo de Ideologia e Urbanização, no final de 1970. Todas as disciplinas que fiz no mestrado foram fundamentais para minha formação: Antropologia Urbana - prof. Anthony Leeds; Dimensões do Conhecimento Etnológico - prof. Luiz de Castro Faria; Sociedades camponesas - prof. Roberto Cardoso de Oliveira; Minorias Nacionais - profa. Francisca Isabel Schuring Vieira; Antropologia das Sociedades Complexas - profs. Richard N. Adams e Shleton H. Davis; Sociologia do Desenvolvimento Latino-Americano - prof. Jorge P. Graciarena; Estratificação Social — profa. Neuma Aguiar Walker; e Poder e Propriedade da Terra e Sociedades Campesinas - prof. Shelton H. Davis. Contei sempre com todo o apoio do então coordenador do PPGAS, professor Roberto Cardoso de Oliveira. O meu orientador foi o Doutor Shelton Davis, na época pesquisador e professor visitante. O diálogo com os professores em geral e com vários colegas foi importante no desenvolvimento de meu trabalho no mestrado. Era um ambiente estimulante e de intensa vida intelectual.

Durante o curso, fui aluno de dois professores da Universidade do Texas, os Drs. Anthony Leeds e Richard Adams, respectivamente, nas disciplinas de Antropologia Urbana e Antropologia das Sociedades Complexas. Assim, com o apoio do professor Roberto Cardoso de Oliveira, recebi uma bolsa da Fundação Ford para fazer cursos como "Special Student" no Departamento 
de Antropologia da Universidade do Texas, em Austin, durante o ano de 1971. Ali, além dos dois professores já mencionados, realizei cursos e estabeleci relações com os Drs. Ira Buchler, Henry Selby, Richard Schaedel e Márcia Hendon. O curso do Dr. Buchler foi fundamental para todo o desenvolvimento de minha carreira. Tive oportunidade de conhecer melhor a obra de Erving Goffman e de travar conhecimento com os trabalhos de Howard S. Becker, de quem viria a me tornar colega e amigo. Em geral, a minha estadia em Austin foi extremamente positiva pelos cursos que fiz, pelos contatos que estabeleci e pelo acesso à excepcional biblioteca. Ainda em 1971, durante o verão, por iniciativa de nosso orientador, o Dr. Richard Adams, eu e minha ex-mulher, a antropóloga Yvonne Maggie, fomos para Cambridge, Massachussets. Na ocasião, estava em Harvard como "Visiting Scholar" o professor Roberto Cardoso de Oliveira. Contávamos também com o professor David Maybury-Lewis, professor de Harvard, ex-professor do PPGAS, e ainda com o Dr. Shelton Davis, que retornara aos Estados Unidos. Realizamos uma pesquisa junto à população portuguesa da Nova Inglaterra que foi muito útil para o meu treinamento e aperfeiçoamento. Foi uma experiência rica e plenamente incorporada à minha formação. $\mathrm{O}$ fato de ter trabalhado na área metropolitana de Boston proporcionou-me a oportunidade de lidar com uma sociedade em que as diferenças e a heterogeneidade saltavam aos olhos, coexistindo de modo ambíguo e tenso. Mas, sobretudo, vivi a forte experiência de investigar relações entre minorias étnicas, culturais, desviantes e as instituições da sociedade norte-americana. A leitura dos livros de W. Foote-White e Herbert J. Gans ajudou-me a lidar com essa profusão de estilos de vida e "taste cultures". Foi uma pesquisa que complementou e enriqueceu de modo decisivo a minha experiência anterior de Copacabana e veio a ajudar-me na pesquisa seguinte no Brasil sobre uso de tóxicos e visão de mundo, que resultou na minha tese de doutoramento, Nobres e Anjos, um Estudo de Tóxicos e Hierarquia.

Regressando ao Brasil em 1972, retomei as minhas atividades docentes no Instituto de Filosofia e Ciências Sociais e iniciei a minha trajetória de professor do Programa de Pós-Graduação em Antropologia Social. No $1^{\circ}$ semestre de 1972, dei meu primeiro curso de Antropologia Urbana. Fui transferido do Instituto de Filosofia e Ciências Sociais para o Departamento de Antropologia do Museu Nacional em dezembro de $1973 .^{2}$ Assim, entrei para a Universidade Federal do Rio de Janeiro, em $1^{\circ}$ de março de 1969, como professor do IFCS, comecei a lecionar no PPGAS em março de 1972, mantendo o meu vínculo principal com o Departamento de Ciências Sociais do IFCS até o final de 1973. Em 1974, ainda ali, dei cursos regulares, embora já lotado no Departamento de Antropologia do Museu Nacional. 
O meu processo de transferência foi possível graças ao apoio do professor Roberto DaMatta, então coordenador do PPGAS, do professor Darcy de Oliveira Albuquerque, diretor do Museu Nacional, e do professor Eduardo Prado Mendonça, diretor do IFCS. Esta mudança de inserção institucional melhorou, significativamente, as minhas condições de trabalho.

A partir de 1982 tornei-me pesquisador I-A do CNPq. ${ }^{3}$ Tenho contado também, desde o meu ingresso no PPGAS, com apoio financeiro da Fundação Ford e da FINEP, através de convênios institucionais para o desenvolvimento de minha atividade de pesquisa.

Em 1973, ingressei no Doutorado do Departamento de Ciências Sociais, Faculdade de Filosofia, Ciências e Letras da Universidade de São Paulo. Tive o privilégio de ter como orientadora a antropóloga Ruth Cardoso, na ocasião, por razões administrativas, localizada na área de Ciência Política. Desenvolvi minha pesquisa sobre uso de tóxicos e visão de mundo/ estilo de vida de camadas médias urbanas no Rio de Janeiro. Defendi a tese, obtendo o grau de Doutor em dezembro de 1975, perante banca presidida por minha orientadora e composta pelos professores Doutores Eunice Durham, Juarez Brandão Lopes, Peter Fry e Mário Bick. ${ }^{4}$

Em janeiro de 1976, menos de um mês depois da defesa de doutorado, viajei para os Estados Unidos, onde permaneci como "Visiting Scholar" até o início de março no Departamento de Sociologia da Northwestern University, Evanston, Illinois. Nessa ocasião, comecei o meu trabalho de parceria com o Dr. Howard S. Becker, ponto de partida para uma rica relação acadêmica e pessoal. Nesse período nos Estados Unidos, tive ocasião de proferir palestras e conferências, participar de seminários, além de trabalhar em

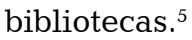

\section{Realizações profissionais}

\section{II.1 Áreas de pesquisa científica, produção intelectual e publicações; preocupações e definições teóricas}

Desde o início de minha carreira, ainda na faculdade, interessei-me pelo universo de camadas médias. Foi e continua sendo uma das principais áreas de investigação e campo para testar e elaborar questões teóricas mais abrangentes. ${ }^{6}$ Paralelamente, fui direcionando minha atenção para os estudos de desvio e comportamento desviante, muito influenciado por Erving Goffman e Howard S. Becker. A bibliografia antropológica sobre acusações de feitiçaria com que travei conhecimento já no mestrado reforçou esse meu interesse. ${ }^{7}$ 
Os trabalhos de Evans-Pritchard, Mary Douglas e o contato com os professores Ira Buchler e Henry Selby, no Texas, ajudaram-me a melhor integrar os trabalhos de Antropologia Social, propriamente dita, com a Sociologia de inspiração interacionista. Um autor fundamental que fui descobrindo, aos poucos, é Georg Simmel. Certamente é uma exploração que ainda não terminou. Seu trabalho como pensador, difícil de classificar ou rotular, tem sido muito instigante para a minha atividade intelectual e de pesquisador. Consequentemente, a temática indivíduo e sociedade, com todas as suas implicações e abrangência, é central tanto para minha atividade de pesquisa como de ensino. O meu trabalho de campo propriamente dito e os principais focos de minha atenção têm se localizado no meio urbano, particularmente na grande metrópole. Daí a minha atuação na área denominada Antropologia Urbana. As questões da organização social do meio urbano, da mobilidade, da diversidade e heterogeneidade constituem preocupações recorrentes em minha trajetória. ${ }^{8}$

Tanto no meu trabalho, como no de meus orientandos, uma outra vertente é a área de família e parentesco. A questão do indivíduo e de sua trajetória sociocultural permanece estratégica. Evidentemente, todos esses temas se entrecruzam, retomando conceitos e ideias mais gerais. ${ }^{9}$

Ligado às problemáticas da Antropologia Urbana e do Desvio, há o destaque necessário para os trabalhos que venho realizando sobre violência. Estão também articulados a temáticas já mencionadas, como família e parentesco, organização social no meio urbano e indivíduo e sociedade. ${ }^{10}$

A Antropologia das Sociedades Complexas, como preocupação teórica e foco de pesquisa, é uma das linhas centrais de toda a minha carreira. A problemática da construção dos diferentes domínios e níveis de realidade, o trânsito e as relações entre estes, a noção de indivíduo e as ideologias associadas são alguns dos temas que se somam e se interligam. Os estudos de camadas médias e de desvio, além do seu interesse específico, serviram sempre de base para o desenvolvimento dessas reflexões de caráter mais geral a que continuo me dedicando. ${ }^{11}$

Cabe frisar que, pela natureza de meus interesses, mantenho contato com áreas da Sociologia e da Ciência Política, como o estudo de elites, a estratificação social em geral, as pesquisas urbanas, ideologia e representação, estudo de carreiras e profissões etc.

A História, como disciplina e como perspectiva, sempre teve grande relevância para mim desde os primórdios de minha formação intelectual. Nos últimos anos, tenho cada vez mais me preocupado, como professor e pesquisador, com as relações entre Antropologia e História. O que se denomina de "Nova História" e/ou "História das Mentalidades", produzida no exterior 
e no Brasil, constitui-se crescentemente em instrumento indispensável para o desenvolvimento de uma Antropologia das Sociedades Complexas. As obras de Jacques Le Goff e Georges Duby são, por exemplo, fundamentais para esse tipo de reflexão que tenho procurado conduzir. Os meus últimos artigos expressam, de algum modo, essa direção. ${ }^{12}$ No momento, desenvolvo pesquisa sobre "Tradições Culturais e Representações de Poder" em que a pesquisa histórica tem papel crucial, complementando o trabalho de campo e a observação participante do antropólogo. De algum modo, estou tentando fazer, singelamente, uma revisão parcial da História do Brasil para melhor me guarnecer em minhas investidas teóricas.

Vale mencionar uma outra antiga e persistente preocupação. Os meus primeiros trabalhos publicados foram na área de Sociologia da Arte. ${ }^{13}$ No decorrer de minha carreira, prossegui, em diferentes momentos, refletindo e publicando dentro desta temática. ${ }^{14}$ Não pretendo abandoná-la, pois sempre me ajudou a abordar de modo diferente o estudo das sociedades complexas.

Uma outra área de interesse ligada à minha atuação como membro dos antigos Conselho da SPHAN, Federal de Cultura e atualmente no Patrimônio Cultural é o papel e o trabalho do antropólogo diante da pesquisa e da política do chamado patrimônio nacional. ${ }^{15}$ Trata-se de mais um desdobramento de preocupações que já apareciam em trabalhos meus de Sociologia da Arte e Antropologia Urbana.

Creio que é importante salientar o esforço de pesquisar e refletir sobre esta atividade no seio da própria sociedade do investigador. Escrevi alguns textos que discutem explicitamente as peculiaridades, dificuldades e características deste tipo de investigação. ${ }^{16}$

É difícil resumir uma produção razoavelmente diversificada de vinte e muitos anos de trabalho. Os recortes que estabeleço são inevitavelmente arbitrários. Considero fundamental deixar claro que todas essas preocupações remetem a questões mais gerais ainda na área da Teoria da Cultura e da Sociedade.

Retrospectivamente, creio que no início de minha atividade de pesquisa e nos meus primeiros trabalhos, como a Utopia Urbana (defendida em 1970, publicada em 1973), está muito presente um pensamento sociológico de raízes marxistas, embora já dialogando com a Antropologia Social propriamente dita. De qualquer forma, a problemática básica era a relação entre experiência social e ideologia e/ou representação. Mais adiante, soma-se, de maneira mais decisiva, através da problemática do desvio, a influência do interacionismo. A coletânea Desvio e Divergência (1973) e a tese Nobres e Anjos (1975) são expressão disto. Vejo no livro Individualismo e Cultura 
(1981) e nas pesquisas associadas a passagem para uma tentativa de síntese entre uma preocupação mais global com a Teoria da Cultura e das Sociedades Complexas e as formulações anteriores. Penso ter trabalhado nessa direção nos últimos dez anos. O livro Subjetividade e Sociedade (1985) visa estabelecer uma reflexão mais integrada sobre trajetória individual e campo de possibilidades sociocultural, trabalhando com a noção de geração.

Os meus últimos trabalhos subordinam-se a um projeto consciente de juntar uma visão antropológica, de códigos e redes de significado, com uma perspectiva histórica, especialmente no artigo "Indivíduo e Religião na Cultura Brasileira" (1991). Pretendo, através do caso brasileiro, levantar questões de interesse mais geral sobre a sociedade moderna contemporânea, especialmente no que toca às representações do indivíduo e à construção social da realidade como processo. Como já mencionei, nos meus planos é crucial uma revisão da bibliografia sobre História do Brasil, tendo em mente as questões acima mencionadas, para procurar compreender não só "como as coisas são", mas "como se tornaram o que são".

Como muitos de minha geração, fui fortemente influenciado pelo marxismo. Autores marxistas ou de inspiração marxista foram leitura frequente desde o curso secundário. Além dos clássicos Marx, Engels e bem menos Lenin, quero enfatizar C. Wright Mills, como um pensador de esquerda, "new left", ligado também a certos valores liberais, como básico na minha formação. Sua preocupação com a biografia individual e sua relação com a história e a sociedade como um todo marcaram-me profundamente.

O meu interesse por Sociologia da Arte levou-me a conhecer, em parte, as obras de Georg Lukács e Lucien Goldman que, também desde o final do curso secundário, constituíram-se em leitura frequente.

O dado "liberal" de minha trajetória se deve também à leitura de Lionel Thrilling, eminente crítico literário e pensador norte-americano, cujos trabalhos conheci através da Sociologia da Arte. Creio que seu trabalho reforçou certas preocupações minhas em torno da liberdade relativa dos artistas enquanto agentes sociais.

Como disse, a temática Indivíduo e Sociedade sempre foi central no desenvolvimento de meu trabalho. Isto se expressa na tentativa de discutir e aproveitar as obras do já mencionado Georg Simmel e de Louis Dumont. A tradição interacionista associada ao primeiro, com desdobramentos contemporâneos em Herbert Blummer, Everett Hughes, Erving Goffman, Howard S. Becker, entre outros, tem sido referência constante para a minha atividade. Por outro lado, Dumont com toda a escola sociológica francesa, principalmente, e Marcel Mauss constituem para mim digamos, o outro polo fundamental da discussão Indivíduo e Sociedade. A escola de Personalidade 
e Cultura, embora tenha indiscutível contribuição, teve menor peso na minha trajetória. Devo salientar a importância da leitura de Gregory Bateson e, em menor grau, de Ruth Benedict e Margaret Mead. Os trabalhos que escrevi sobre desvio têm toda essa literatura como pano de fundo. Mas o tema Indivíduo e Sociedade é mais abrangente e a minha produção em geral está implícita ou explicitamente vinculada a essa linha de reflexão. Não posso esquecer a enorme importância de Alfred Schultz, pensador, combinação de filósofo e sociólogo, cuja obra conheci no início da década de 1970. Desde então, constantemente, vejo-me utilizando suas reflexões e seus diálogos com autores como Simmel e Weber. A noção de projeto passou a ser para mim um dos mais preciosos instrumentos para a discussão de Indivíduo e Sociedade. Max Weber apareceu nas minhas leituras, primeiro, como interlocutor de Marx e, nos últimos dez anos, volto a lê-lo, procurando relacioná-lo a Simmel. Isto não significa desconhecer o valor de sua obra em si mesma, mas registrar como se deu minha relação com as suas ideias. Vale frisar que sua visão de estratificação social, classes, grupos de status etc. foi fundamental para meu trabalho desde o início, assim como seu individualismo metodológico enquanto detonador de questões e indagações para toda a teoria sociológica a que recorri.

A minha aproximação com a Antropologia acelerou-se, nos primeiros tempos de faculdade, através de Claude Lévi-Strauss. Na época, meados dos anos 1970, o estruturalismo virou mesmo uma moda intelectual. Mas, para nós antropólogos, a obra do grande pensador francês foi, sobretudo, um modo de repensar e reinventar toda a história da Antropologia. Devo registrar que suas observações sobre a sociedade moderna contemporânea constituíram-se em um dos principais estímulos do início de minha carreira. Certamente ajudou a solidificar algumas de minhas intenções ainda tímidas e vacilantes.

Na chamada Antropologia Social Britânica, além do já mencionado Evans-Pritchard, registro a importância da leitura de Max Gluckman, Victor Turner e, sobretudo, Edmund Leach particularmente, com o seu Political Systems of Highland Burma. Neste trabalho, a problemática Indivíduo e história/sociedade, com o jogo de papéis e identidades associados à mudança de contextos e situações, marcou-me fortemente. Foi um dos melhores livros que li sobre Complexidade Social.

Dentro da Antropologia contemporânea, Clifford Geertz e Marshall Sahlins têm sido fonte de inspiração para muitos de nós. No meu caso, mais uma vez, a temática Indivíduo/Sociedade e História, como discutida por estes autores, marca boa parte de minhas reflexões. Continuo procurando acompanhar suas produções e transformações. 
Não vou deixar também de enfatizar o diálogo com colegas brasileiros ou que trabalharam no Brasil, de várias gerações. De modos diferentes, em situações e momentos distintos, tenho fortes dívidas com Francisca Keller, Anthony Seeger, Peter Fry, Roberto Cardoso de Oliveira, Roberto DaMatta, Luiz de Castro Faria, Otávio Guilherme Velho, Ruth Cardoso, Eunice Durham, Jether Ramalho, Maurício Vinhas de Queiroz, Evaristo de Moraes Filho, Luiz Fernando Duarte, Eduardo Viveiros de Castro, José Sergio Leite Lopes, Sérvulo Figueira, Roque Laraia, Yonne Leite, Giralda Seyferth, Laura de Mello e Souza, Maria Manuela Carneiro da Cunha, Gilberto Freyre, Yvonne Maggie e Thales de Azevedo.

Seja através de livros e artigos que li, de aulas e conferências a que assisti ou através do insubstituível contato pessoal como aluno, colega ou professor, todas essas pessoas, assim como outras que possa ter omitido, foram ou são interlocutores preciosos. A minha atividade profissional e boa parte de minha vida afetiva estão ligadas, indissoluvelmente, a esses nomes.

\section{II.2 Atividades docentes}

\section{II.2.1 Curso de graduação}

Fui professor de Antropologia no Instituto de Filosofia e Ciências Sociais da UFRJ, de 1969 a 1974. Lecionei diferentes disciplinas, entre as quais o semestre básico de Antropologia, História da Antropologia, Teoria Antropológica, Antropologia Brasileira etc. Alguns dos meus alunos da graduação voltaram a se encontrar comigo no nível da pós-graduação. Certamente, a experiência de dar aulas para turmas em etapa inicial de sua formação universitária foi decisiva e marcante. A atividade docente em qualquer nível sempre me interessou. Através de conferências e palestras e da atuação de alunos, ex-alunos e colegas mantive um vínculo como esse nível de ensino. Devo dizer que considero seriamente a possibilidade de voltar a ensinar em turmas de graduação depois de anos de afastamento.

\section{II.2.2 Pós-graduação}

Como já disse, desde 1972, há vinte anos portanto, sou professor do Programa de Pós-Graduação em Antropologia Social, do Departamento de Antropologia do Museu Nacional da UFRJ. Nesse período, entre outras disciplinas, lecionei Antropologia Urbana, Antropologia das Sociedades Complexas, Indivíduo e Sociedade, Teoria Antropológica, Estrutura Social do Brasil, Teoria da Ideologia e da Cultura e Organização Social e Parentesco. 
Fui professor visitante no Departamento de Ciências Sociais da Faculdade de Filosofia, Letras e Ciências Humanas da Universidade de São Paulo (USP) no $2^{\circ}$ semestre de 1986. Dei o curso Antropologia Urbana para um grupo de alunos que muito me marcou pelo interesse e qualidade. O contato que tive com colegas professores foi também altamente estimulante. Dei ou participei de cursos em nível pós-graduado no Instituto de Psiquiatria, na Faculdade de Educação da UFRJ, no Departamento de Psicologia e Antropologia da Universidade Federal do Paraná, na Universidade Federal do Rio Grande do Norte, no Programa de Pós-Graduação em Ciências Sociais da Universidade Federal de Santa Catarina, Mestrado em Psicologia da Pontifícia Universidade Católica do Rio de Janeiro. Lecionei também nos cursos de formação analítica do Instituto de Medicina Psicológica e da Sociedade de Psicoterapia Analítica de Grupo do Rio de Janeiro.

\section{II.2.3 Congressos, conferências, palestras e seminários}

Ao lado das minhas atividades docentes regulares, no decorrer de minha carreira tenho ministrado conferências e palestras para diferentes tipos de instituições e associações científicas e culturais. Fora da área, convencionalmente classificada como Ciências Sociais - Antropologia, Sociologia e Política - é importante salientar a minha atividade na chamada área PSI. Por diversas ocasiões, ministrei palestras ${ }^{17}$ e conferências ${ }^{18}$ para psicólogos, psiquiatras e psicanalistas. Certamente, esta tem sido uma das áreas inter ou multidisciplinares em que mais tenho atuado. Como é natural em uma trajetória acadêmica de mais de 23 anos, participei de dezenas de congressos no Brasil e no exterior. No país, nas reuniões da Associação Brasileira de Antropologia (ABA), Associação Nacional de Pós-Graduação e Pesquisa em Ciências Sociais (ANPOCS) e da Sociedade Brasileira para o Progresso da Ciência (SBPC), tenho regularmente apresentado trabalhos, participado de seminários e presidido mesas. Além dos já mencionados, tenho apresentado trabalhos e participado de discussões em temas tais como Educação, Violência, Política Científica e Cultural, Problemas Urbanos, Antropologia e Sociologia da Arte, Família e Parentesco, Uso e Consumo de Tóxicos etc.

A minha atividade internacional tem se concentrado nos Estados Unidos. Realizei, pelo menos, uma dúzia de viagens ao exterior para intercâmbio acadêmico. A temática de minhas palestras-conferências tem sido bastante variada, incluindo a problemática brasileira propriamente dita e questões mais gerais de Antropologia e Sociologia. ${ }^{19}$

\section{II.2.4 Formação, orientação de alunos e pesquisadores}

Sempre foi minha preocupação central a orientação de alunos e seu 
treinamento como pesquisadores. A atividade de professor de pós-graduação implica permanente acompanhamento e supervisão do corpo discente. Desde 1976, passei a orientar oficialmente alunos do PPGAS, pois obtive o grau de Doutor na USP em dezembro de 1975. Orientei, desde então, 30 alunos que obtiveram seus graus de mestre e seis que chegaram a doutor, num total de 36 orientandos. Entre os mestres que formei, além dos que concluíram o doutorado no PPGAS, mais quatro obtiveram o título em outras instituições: Rozine Josef Perelberg (London School of Economics, Antropologia, Inglaterra), Marcia Nunes (Northwestern University, Sociologia, Estados Unidos), Carlos Nelson Ferreira dos Santos (Universidade de São Paulo, Arquitetura e Urbanismo), Maria Dulce Gaspar de Oliveira (Universidade de São Paulo, Arqueologia). ${ }^{20}$

Além destes, 12 estão inscritos em curso de doutoramento. Fora do PPGAS, orientei três dissertações de mestrado no Instituto Universitário de Pesquisa do Estado do Rio de Janeiro (IUPERJ), no Programa de Planejamento Urbano e Regional da Coordenação de Pós-Graduação em Engenharia (COPPE/UFRJ) e na Universidade Federal do Rio Grande do Sul; e fui coorientador de outra na Universidade Federal de Santa Catarina. Todos os meus orientandos ingressaram ou prosseguiram suas atividades acadêmicas em instituições universitárias e de pesquisa: Universidades Federais do Rio de Janeiro, Federal Fluminense, Rio Grande do Sul, Paraná, Universidade do Estado do Rio de Janeiro (UERJ), Pontifícia Universidade Católica do Rio de Janeiro (PUC/RJ), Instituto Superior de Estudos da Religião (ISER), Instituto Brasileiro de Geografia e Estatística (IBGE) etc.

Também integrei como membro um total de 39 bancas de mestrado, das quais 28 no próprio PPGAS e as outras onze na Antropologia Social da Universidade de Brasília, Psicologia - Pontifícia Universidade Católica do Rio de Janeiro, Instituto Universitário de Pesquisas do Rio de Janeiro, Universidade Federal da Bahia, Ciências Sociais/ Universidade de São Paulo, Ciências Sociais - Universidade Federal do Rio de Janeiro (UFRJ). Como já disse, no nível de doutorado, orientei no PPGAS seis alunos que já obtiveram o grau de Doutor. Participei de mais quatro bancas de doutorado no PPGAS, uma no Departamento de Ciências Sociais da USP e outra no IUPERJ. ${ }^{21}$

Os meus orientandos, em alguns casos, trabalharam sob minha supervisão não só como alunos individuais, mas como membros de equipes de trabalho. Na área de família e parentesco, por exemplo, isto ocorreu no caso das hoje Doutoras Myriam Moraes Lins de Barros, Tania Dauster Magalhães e Silva, Tania Rachel Salem e Maria Cecília Solheid da Costa. No tema da juventude, foi formada uma equipe com as atuais mestres Claudia Rezende, Silvia Fiuza e Maria Claudia Coelho. Há que mencionar os alunos que 
também foram meus assistentes de pesquisa: Eduardo Viveiros de Castro, Myriam Moraes Lins de Barros, Ovídio de Abreu Filho, Maria Luiza de Amorim Heilborn, Claudia Rezende e Carla Costa Teixeira.

Assim, na medida do possível, através de cursos, seminários e grupos de trabalho, busquei uma maior integração entre os projetos dos alunos.

Procurei sempre estimular, e na medida do possível ajudar, a publicação de teses, dissertações e artigos que julgasse de boa qualidade e de interesse para um público maior. Publicaram livros a partir de seus trabalhos acadêmicos os meus alunos ou ex-alunos Luiz Fernando Duarte, Carlos Nelson F. dos Santos, Carlos Albuquerque Messeder Pereira, Myriam Moraes Lins de Barros, Sandra Carneiro, Maria Dulce Barcelos Gaspar de Oliveira, Hermano Vianna Junior, Luis Rodolfo Vilhena e Celso Castro.

\section{Atividades complementares}

\section{Cargos acadêmicos, administrativos, política científica e cultural}

No âmbito do PPGAS, fui subcoordenador de Atividades Culturais (agosto 76 a agosto 78) e coordenador do Programa de Pós-Graduação em Antropologia Social (agosto 78 a agosto 80). Chefiei o Departamento de Antropologia do Museu Nacional de $1^{\circ}$ de setembro de 1982 a $1^{\circ}$ de setembro de 1984. Fui representante dos professores assistentes e dos professores adjuntos na Congregação do Museu Nacional (1976 a 1979; 1980 a 1982). Ao lado de minhas atividades no âmbito do PPGAS e no Departamento de Antropologia como um todo, fui progressivamente me envolvendo em tarefas ligadas às sociedades científicas de que faço parte e a outras relacionadas com a situação dos campos científico e cultural do país. Assim, é que fui membro do Comitê Assessor do Conselho Nacional de Desenvolvimento Científico e Tecnológico (CNPq) [jan. 1980 a dez. 1981] e presidente da Comissão de Consultores Científicos da Coordenação de Aperfeiçoamento de Pessoal de Nível Superior (CAPES) [fev. a dez. 1984]. Em 1981, assumi a coordenadoria geral da Área de Ciências Sociais no projeto Avaliação e Perspectivas do CNPq (1981-1982). Em 1982, tornei-me membro da Comissão da Secretaria de Planejamento da Presidência da República/ Academia Brasileira de Ciências/ Sociedade Brasileira para o Progresso da Ciência (SEPLAN/ABC/SBPC) para reavaliação do sistema nacional de desenvolvimento científico e tecnológico (out. 1982 a set. 1983). De abril de 1985 a abril de 1986, fui membro da Comissão de Pesquisadores indicada pelas Sociedades Científicas para retomar a problemática da Comissão SEBLAN/ 
ABC/SBPC. Fui conselheiro da Associação Brasileira de Antropologia (ABA) em dois períodos: maio de 78 a abril de 82; abril de 84 a abril de 86 . Fui presidente desta Associação de abril de 82 a abril de 84. Certamente, a minha experiência como presidente da ABA foi uma das mais ricas e estimulantes de toda a minha carreira, com a oportunidade de lidar diretamente com colegas, temas e problemas em situações as mais diversas. De há muito tenho atuado na Sociedade Brasileira para o Progresso da Ciência (SBPC) não só nos congressos, mas na formulação e encaminhamento de suas orientações. Fui membro do Conselho Regional-Rio da SBPC (1982-1983) e por duas vezes membro do seu Conselho Científico Nacional (set. 1983 a ago. 1987; jul. 1989 a jul. 1993). Desde dezembro de 1991, assumi uma das vice-presidências da Sociedade. ${ }^{22}$

Tenho também participado de Conselhos ligados ao governo federal. Em 1983, fui nomeado membro do Conselho do Patrimônio Histórico e Artístico Nacional, Secretaria da Cultura (SPHAN). Em 1990, com o governo Collor e com a reforma administrativa, a situação deste conselho ficou bastante indefinida devido à extinção de vários órgãos e do próprio Ministério da Cultura. Foi recentemente, em parte, restaurado com a criação do Conselho Consultivo do Patrimônio Cultural do Instituto Brasileiro do Patrimônio Cultural da Secretaria de Cultura. Em 23 de janeiro de 1992, fui nomeado membro do novo Conselho, juntamente com todos os antigos representantes da sociedade civil no Conselho da SPHAN. Também integrei o Conselho Federal de Cultura, no antigo Ministério da Cultura. Ali atuei por cerca de seis meses, renunciando devido à dificuldade de compatibilizar minhas atividades e por questionar a forma de seu funcionamento (out. 1987 a abr. 1988).

A partir da minha atuação na Associação Brasileira de Antropologia e na Sociedade Brasileira para o Progresso da Ciência e em diversas Comissões das Sociedades Científicas, tornei-me membro do Conselho Deliberativo do Conselho Nacional de Desenvolvimento Científico e Tecnológico (CNPq), que integrei de agosto de 1986 a julho de 1988. Esta foi mais uma experiência marcante, que me permitiu ter uma visão geral do campo científico brasileiro e conhecer melhor problemas e colegas de outras áreas.

Desde o início da minha carreira, antes mesmo de me formar, desenvolvi uma série de trabalhos e iniciativas de caráter editorial. Dirigi a Coleção de Antropologia Social da Zahar Editores de 1974 a 1985, continuando diretor na nova Editora Jorge Zahar até os dias de hoje. A partir de 1967, organizei os quatro volumes da Coleção de Sociologia da Arte, Coleção Textos Básicos de Ciências Sociais daquela Editora. Fui organizador ou coorganizador de outras coletâneas, como Desvio e Divergência e O Desafio da Cidade. ${ }^{23}$ 
Participei e participo de Conselhos Editoriais, de Redação e Científicos de revistas como Civilização Brasileira, Anuário Antropológico, Revista de Antropologia da USP e Ciência Hoje.

Tenho tido na minha carreira a preocupação de me manifestar publicamente, através de artigos assinados em jornais. De 1979 até hoje publiquei 30 artigos no Jornal do Brasil, O Globo e na Folha de São Paulo. ${ }^{24}$ O conteúdo destes versa ora sobre assuntos diretamente ligados ao meu trabalho de antropólogo, ora sobre temas de caráter mais geral que discuto, procurando trazer uma contribuição para um público maior.

Esta foi uma tentativa de traçar as linhas gerais de uma trajetória profissional. Forçosamente, existem falhas e omissões neste relato. No entanto, a experiência de prepará-lo, de algum modo, enriqueceu a visão que tenho não só de mim mesmo, mas sobretudo de uma rede de relações e de um período das Ciências Sociais no Brasil. Ajuda-me também a continuar o meu trabalho, de certa forma, renovado.

Rio de Janeiro, junho de 1992.

Gilberto Cardoso Alves Velho

\section{Notas}

${ }^{1}$ Coordenados, respectivamente, pelos professores Maurício Vinhas de Queiroz e Maria Stella de Amorim.

${ }^{2}$ Gilberto atuou como auxiliar de ensino de Antropologia no IFCS/UFRJ a partir de março de 1969, tendo sido "aprovado quanto ao mérito para a promoção a professor-assistente em dezembro de 1972" e lotado no Departamento de Antropologia do Museu Nacional a partir de dezembro do ano seguinte.

${ }^{3}$ Alguns anos mais tarde, Gilberto Velho tornou-se pesquisador sênior do CNPq.

${ }^{4}$ Nobres \& Anjos: um estudo de tóxicos e hierarquia. Defendida em 1975 na Universidade de São Paulo, sob orientação da professora Ruth Cardoso.

${ }^{5}$ Nas seguintes instituições: Universidade de Wisconsin, em Milwaukee; no Center for Urban Affairs da Northwestern University, em Illinois; no Interdisciplinary Seminar on Brazil da Columbia University, em Nova York; na Newbery Library, em Chicago e na Boston University, em Boston. 
${ }^{6}$ No memorial, Gilberto destacou os seguintes trabalhos como dignos de nota a este respeito: A utopia urbana: um estudo de ideologia e urbanização. Dissertação de Mestrado, defendida no PPGAS, Museu Nacional, UFRJ e homologada em março de 1971; "Organização social do meio urbano" [com L. A. Machado]. Anuário Antropológico, 1976; "Cotidiano e política num prédio de conjugados". In: J. A. Guilhon de Albuquerque (org.), Classes médias e políticas no Brasil. Rio de Janeiro: Paz e Terra, 1977; "Academicismo e vida universitária", Encontros com a Civilização Brasileira, 16, 1979; "O antropólogo pesquisando em sua cidade: sobre conhecimento e heresia". In: O desafio da cidade - novas perspectivas da antropologia brasileira. Rio de Janeiro: Campus, 1980; "A busca de coerência: coexistência e contradições entre códigos em camadas médias urbanas". In: S. Figueira (org.), Cultura da psicanálise no Brasil. Psicanálise e psicologia na sociedade contemporânea. São Paulo: Brasiliense, 1985; "Conformación de la cultura moderna de classe media en Brasil: una perspectiva antropologica". In: R. Morse; J. E. Hardoy (orgs.), Cultura urbana latino-americana. Buenos Aires: Clacso, 1985.

${ }^{7}$ No memorial, Gilberto mencionou os seguintes trabalhos: Nobres \& Anjos um estudo de tóxicos e hierarquia. Tese de doutoramento, USP, 1975; "Estigma e comportamento desviante em Copacabana". América Latina, ano 14, n. 1/2, janeiro-junho de 1971; "Accusations, family mobility and deviant behavior". Social Problems, 23(3), 1976; "Relações entre antropologia e psiquiatria". Revista da Associação de Psiquiatria e Psicologia da Infância e Adolescência, v. 2, 1976; "Vanguarda e desvio". In: G. Velho (org.), Arte e Sociedade - ensaios de sociologia da arte. Rio de Janeiro: Zahar Editores, 1977; "Stigmatization and deviance in Copacabana". Social Problems, 25(5), 1978; "Literatura e desvio: questões para a antropologia". In: Caminhos cruzados. São Paulo: Brasiliense, 1982; "O consumo de cannabis e suas representações culturais". In: M. Sabina (org.), Maconha em debate. São Paulo: Brasiliense, 1985.

${ }^{8}$ Gilberto faz referência aos seguintes trabalhos: A utopia urbana: um estudo de ideologia e urbanização. Dissertação de Mestrado, defendida no PPGAS, Museu Nacional, UFRJ e homologada em março de 1971; Organização e introdução de O desafio da cidade - novas perspectivas da antropologia brasileira. Rio de Janeiro: Ed. Campus, 1980; "Organização social do meio urbano" [com L. A. Machado]. Anuário Antropológico, 1976; "Favelas cariocas: o problema da marginalidade". Anuário Antropológico, 1976; "Estilo de vida e cultura urbana". Anais do Simpósio de Planejamento Urbano e Habitacional, NEURB, PUC/RJ, 1978; "O antropólogo pesquisando em sua cidade: sobre conhecimento e heresia". In: O desafio da cidade novas perspectivas da antropologia brasileira. Rio de Janeiro: Campus, 1980; "A grande cidade brasileira: sobre heterogeneidade e diversidades culturais". Revista do Patrimônio Histórico e Artístico Nacional, 21, 1986.

${ }^{9}$ Gilberto menciona especialmente os seguintes trabalhos: Coordenador [juntamente com Sérvulo A. Figueira] de Família, psicologia e sociedade. Rio de Janeiro: Ed. Campus, 1981; "A crise normal da adolescência" [com Carlos Castellar, Carlos Byington e Eduardo Kalina], Saúde em Debate. Revista do Centro Brasileiro de Estudos da Saúde, 3, 1977; "Parentesco, individualismo e acusações". In: Família, psicologia e sociedade. Rio de Janeiro: Ed. Campus, 1981; "Aliança e casamento na sociedade 
moderna: separação e amizade em camadas médias urbanas". Boletim do Museu Nacional, 39, 1983.

${ }^{10}$ No memorial, Gilberto faz referência aos seguintes trabalhos: "Violência e cidadania". Dados - Revista de Ciências Sociais, 23(3), 1980; "Violência e relações sociais: a questão da diferença". Revista de Ciências Sociais, 12/13(1-2), 1981/1982; "As vítimas preferenciais". Suplemento, Encarte especial Violência, Revista Ciência Hoje, janeiro-fevereiro, 1987; "O cotidiano da violência: identidade e sobrevivência". Boletim do Museu Nacional, Série Antropologia, 56, 1987; "Destino; campo de possibilidades e províncias de significado: notas sobre a violência". Comunicação do PPGAS, 16, 1989; "O grupo e seus limites". Dossiê Violência, Revista USP, 9, 1991.

${ }^{11}$ Gilberto cita especialmente Individualismo e cultura — notas para uma antropologia da sociedade contemporânea. Rio de Janeiro: Zahar Editores, 1981.

${ }^{12}$ Textos mencionados por Gilberto: "Destino; campo de possibilidades e províncias de significado: notas sobre a violência". Comunicação do PPGAS, 16, 1989; "A vitória de Collor: uma análise antropológica". Novos Estudos CEBRAP, 26, 1990; "Indivíduo e religião na cultura brasileira". Novos Estudos CEBRAP, 31, 1991.

${ }^{13}$ Gilberto menciona a organização e introdução dos volumes I, II, III e IV de Sociologia da arte, da Coleção Textos Básicos de Ciências Sociais, da Zahar Editores (1966, 1967, 1968); Organização de Arte e sociedade - ensaios de sociologia da arte. Rio de Janeiro: Zahar Editores, 1977 e o texto "Para que sociologia da arte no Brasil?". Cadernos Brasileiros, ano IX, n. 40, março/abril de 1967.

${ }^{14}$ Trabalhos citados por Gilberto: "Literatura e desvio: questões para a antropologia". Caminhos cruzados. São Paulo: Brasiliense, 1982; "Antropologia e literatura: a questão da modernidade", Comunicação do PPGAS, 12, 1988. "Teatro político e pluralismo cultural", Caderno Especial do Jornal do Brasil, 1979.

${ }^{15}$ Textos mencionados por Gilberto: "Antropologia e patrimônio cultural". Revista do Patrimônio Histórico e Artístico Nacional, 20, 1984; "A grande cidade brasileira: sobre heterogeneidade e diversidades culturais". Revista do Patrimônio Histórico e Artístico Nacional, 21, 1986.

${ }^{16}$ Trabalhos mencionados por Gilberto: "O estudo do comportamento desviante: a contribuição da antropologia social" e "Estigma e comportamento desviante em Copacabana". In: Desvio e Divergência: uma crítica da patologia social. Rio de Janeiro: Zahar Editores, 1974; "Observando o familiar". In: E. Nunes (org.), Aventura sociológica. Rio de Janeiro: Zahar Editores, 1978; "O antropólogo pesquisando em sua cidade: sobre conhecimento e heresia". In: O desafio da cidade - novas perspectivas da antropologia brasileira. Rio de Janeiro: Ed. Campus, 1980.

${ }^{17}$ Por exemplo, no IV Simpósio sobre Emergências Psiquiátricas, Instituto de Psiquiatria da UFRJ, em 1973; no III Congresso Brasileiro de Psiquiatria, promovido pela Associação Brasileira de Psiquiatria em 1974; na $4^{\mathrm{a}}$ Reunião do Forum 
Panamericano para o Estudo da Adolescência, 1977; no I Simpósio Internacional de Psicanálise, Grupos e Instituições, ocorrido no Rio de Janeiro, 1978; no II Simpósio Nacional de Psicologia Clínica, promovido pelo Centro de Psicologia Social, Rio de Janeiro, 1980; no Simpósio sobre Dependência a Drogas, realizado no Instituto de Psiquiatria da UFRJ, em 1980.

${ }^{18}$ No Instituto de Psiquiatria da UFRJ, em 1973; na Abertura Oficial dos Cursos do Instituto da Sociedade Brasileira de Psicanálise, em 1974; no Simpósio sobre "Emergências psiquiátricas", promovido pela Associação Brasileira de Psiquiatria da Infância e da Adolescência, Rio de Janeiro, 1974; no Simpósio "50 Anos de Psiquiatria", promovido pelo Instituto de Psiquiatria da UFRJ, em 1975; na Sociedade Brasileira de Psicanálise de Grupo, 1979; no Grupo de Estudos Psiquiátricos do Hospital do Servidor Público Estadual "Francisco Morato de Oliveira", São Paulo, 1980; na Associação Brasileira de Psiquiatria, Rio de Janeiro, 1981; no Instituto de Psicologia da Universidade Federal do Rio de Janeiro, 1982; no curso de Pós-Graduação do Instituto de Psiquiatria da UFRJ, em 1990.

${ }^{19}$ Gilberto mencionou especificamente sua participação na National Drug Abuse Conference, em São Francisco, 1977; no 6th Annual Sociology of the Arts Conference, em New Jersey, 1979; no 8th International Symposium on Urbanization in the Americas, nas Universidades de Stanford e Berkeley, California, 1982, no II Congresso Argentino de Antropologia Social, Buenos Aires, 1986; bem como atividades realizadas nas instituições citadas na nota 5.

${ }^{20}$ A listagem completa de orientandos de mestrado e doutorado de Gilberto Velho encontra-se no anexo, ao final deste texto.

${ }^{21}$ Ao longo de sua trajetória, Gilberto participou como membro de bancas de mestrado e doutorado em instituições as mais diversas, tais como UFRJ, UERJ, USP, IUPERJ, UNICAMP, Fundação Getúlio Vargas, Universidad Nacional de Misiones, UFRGS, PUC-Rio, Universidade Federal de Santa Catarina, UnB, Universidade Gama Filho, IPPUR-UFRJ, ISCTE Lisboa, UFF entre outras.

${ }^{22}$ A qual deixou em julho de 1993.

${ }^{23}$ Desvio e divergência. Uma crítica da patologia social. Rio de Janeiro: Zahar Editores, 1974; O desafio da cidade: novas perspectivas da antropologia brasileira. Rio de Janeiro: Campus, 1980.

${ }^{24}$ Em seu currículo Lattes (consultado em junho de 2012), são citadas 107 matérias de sua autoria publicadas em jornais e revistas variados. 


\section{Anexo 1 - Publicações}

\section{Artigos completos publicados em periódicos}

1. VELHO, G. 2011. "Antropologia urbana: interdisciplinaridade e fronteiras do conhecimento". Mana. Estudos de Antropologia Social, 17(1):161-185.

2. VELHO, G. 2011. "Urban anthropology. Interdisciplinarity and boundaries of knowledge". Vibrant, 08(2):451-479.

3. VELHO, G. 2010. "Metrópole, cosmopolitismo e mediação". Horizontes Antropológicos, 1.

4. VelHo, G. 2009. "Ruth Cardoso". Jornal da Ciência.

5. VelHo, G. 2009. "Ruth Corrêa Leite Cardoso". Vibrant, 6.

6. VELHO, G. 2009. "Antropologia urbana: encontro de tradições e novas perspectivas". Sociologia (Lisboa), 1:1-1.

7. VELHO, G. 2009. "Antropologia e a problemática da classe social". Interseções (UERJ), 2:297-305.

8. VELHO, G. 2008. "Pesquisa e descoberta em ciências sociais". Os descobrimentos do Brasil pela ciência, 5:109-130.

9. VelHO, G. 2008. "Ruth Corrêa Leite Cardoso". Dados (Rio de Janeiro), 51:271.

10. VELHO, G. 2008. "Introdução ao Dossiê Homenagem aos fundadores". Mana. Estudos de Antropologia Social (Rio de Janeiro), 14(2):543-546.

11. VELHO, G. 2008. "Goffman, mal-entendidos e riscos interacionais". Revista Brasileira de Ciências Sociais, 23:145-148.

12. VELHO, G. 2008. "Gilberto Freyre: trajetória e singularidade". Sociologia (Lisboa), $58: 11-21$.

13. VELHO, G. 2007. "Ciências sociais e biografia individual". Estudos Históricos (Rio de Janeiro), 38:3-10.

14. VELHO, G. 2007. "Rio de Janeiro: sociabilidade e violência". Cahiers des Amériques Latines (Paris), 1-2.

15. VelHO, G. "Campo/contracampo 10 anos de Etnográfica, 20 anos de CEAS". Etnográfica (Lisboa), n. esp., pp. 1-136.

16. VELHO, G. 2006. "Patrimônio, negociação e conflito". Mana. Estudos de Antropologia Social (Rio de Janeiro), 12(1):1-262.

17. VelHO, G. 2006. "De quem é a culpa?". Boletim do Acadêmico, 199:5.

18. VELHO, G. 2006. "Orientação e parceria intelectual: dilemas e perspectivas". Revista Sociedade em Estudos, 1:15-20.

19. VELHO, G. 2006. "O multipertencimento e os jovens do mundo contemporâneo". Cadernos IHU (UNISINOS), 208:22-23.

20. VELHO, G. 2005. "O futuro das ciências sociais e a importância de seu passado". Sociologia (Lisboa), 48:11-18.

21. VELHO, G. 2005. "Rio, cultura e crise". Argumento (Rio de Janeiro), pp. 1-70.

22. VELHO, G.; CARVALHO FILHO, C. A. A.; BARRETO, F. C. S.; JORNADA, J. A. H.; BEVILACQUA, L.; DAVIDOVICH, L.; NUSSENZVEIG, M.; GATASS, R.; CHAVES, A. S. 2004. "Subsídios para a Reforma da Educação Superior". Academia Brasileira de Ciências, Rio de Janeiro. 
23. VelHo, G. 2004. "Gregory Bateson". Nova Perspectiva Sistêmica, Rio de Janeiro, 25:29-35.

24. VELHO, G. 2004. "Orientação e parceria intelectual: dilemas e perspectivas". Ilha. Revista de Antropologia (Florianópolis), Florianópolis, 6:133-144.

25. VELHO, G. 2003. "Cultura, sociedade e violência no Brasil". Fórum. Debates sobre justiça e cidadania. Revista da AMAERJ, Rio de Janeiro, pp. 30-33.

26. VELHO, G. 2003. "Sobre a nova edição de 'Coronel, coronéis'". Revista Brasileira, Rio de Janeiro, 1:103-104.

27. VELHO, G. 2002. "A diferença sob o ponto de vista da antropologia." Leituras Compartilhadas, 4.

28. VELHO, G. 2002. "A crise das bolsas". Jornal da Ciência JC Email, Rio de Janeiro, 2037.

29. VELHO, G. 2002. "A grave crise das bolsas do CNPq". Jornal da Ciência, Rio de Janeiro, 482.

30. VELHO, G. 2002. "Becker, Goffman e a antropologia no Brasil". Ilha. Revista de Antropologia, Florianópolis, 4:5-16.

31. VELHO, G. 2001. "Terrorismo, intolerância e cultura". Jornal da Ciência, Rio de Janeiro, pp. 6e11-6e11.

32. VELHO, G. 2001. "Família e parentesco no Brasil contemporâneo: individualismo e projetos no universo de camadas médias". Interseções (UERJ), Rio de Janeiro, 2:45-52.

33. VELHO, G. 2001. "A Universidade pública ameaçada". Jornal da Ciência, Rio de Janeiro, pp. 5-5.

34. VELHO, G. 2001. "Observing the familiar". Indian International Centre Quaterly, Nova Delhi, 28(1):47-57.

35. VELHO, G. 2001. "Entrevista com Gilberto Velho". Estudos Históricos (Rio de Janeiro), 28:183-210.

36. VELHO, G. 2000. "Identidades Nacionais e Cultura Popular: o diálogo entre antropologia e folclore". Série Encontros e Estudos Cultura Material Identidades e Processos Sociais, Rio de Janeiro, 1(3):7-11.

37. VELHO, G. 2000." Antropologia das sociedades complexas: continuidade e mudança no Brasil e em Portugal". Convergência Lusíada Brasil e Port 500 Anos de Enlaces e Desenlaces, Rio de Janeiro, 17, n. esp., pp. 151-162.

38. VELHO, G. 2000. "Individualismo, anonimato e violência na metrópole". Horizontes Antropológicos, A Cidade Moderna, UFRGS - Porto Alegre, 3:15-26.

39. VelHo, G. 2000. "O Desafio da Violência". Estudos Avançados, São Paulo, $14(39): 56-60$.

40. VELHO, G. 1998. Revista de Cultura Brasileña (organizador), Madri, 1(1):1-311.

41. VELHO, G. 1998. "Cultura, identidad y pluralismo sociocultural". Revista de Cultura Brasileña, Madri, 1(1):7-13.

42. VelHo, G. 1998. "O humanismo de Carolina Bori". Psicologia USP, São Paulo, $9(1): 217-217$.

43. VELHO, G. 1998. "Gilberto Velho: um diálogo entre a História e a Antropologia". História e Memória, 8:5-7.

44. VELHO, G. 1998. "Universidade, Autonomia e Qualidade Acadêmica, em Debate sobre Autonomia Universitária". Revista Brasileira de Informação Bibliográfica em Ciências Sociais, Rio de Janeiro, 46:129-131. 
45. VELHO, G. 1998. "Apresentação: Antropologia, Religião e Imagem". Cadernos de Antropologia e Imagem (UERJ), Rio de Janeiro, 2(7):15-16.

46. VELHO, G. 1997. "Memória, tradição e mudança na grande cidade". Arquitetura Revista do IAB - Instituto dos Arquitetos do Brasil, ano 28, Rio de Janeiro, 1(80):4-5.

47. VELHO, G.; REIS, F. W.; REIS, E. P. 1997. "As ciências sociais nos últimos vinte anos: três perspectivas". Revista Brasileira de Ciências Sociais, Rio de Janeiro, 12(35):7-28.

48. VELHO, G. 1997. "Maurício Vinhas de Queiróz (1921-1996)". Anuário Antropológico, Rio de Janeiro, 96:283-285.

49. VELHO, G. 1997. "Desafios e metamorfoses da antropologia contemporânea Entrevista com Gilberto Velho". Etnográficas Iscte, Lisboa, pp. 321-327.

50. VELHO, G. 1996. "Introdução: Homenagem a Florestan Fernandes". Revista Brasileira de Ciências Sociais, 11(30):5-5.

51. VELHO, G.; KUSCHNIR, K. 1996. "Mediação e metamorfose". Mana: Estudos de Antropologia Social, Rio de Janeiro, 2(1):97-107.

52. VELHO, G. 1996. "Os anos 90 e a violência". Eventual 9@, Paço Imperial, Rio de Janeiro, 2:6-7.

53. VELHO, G. 1996. "Crença, transe e possessão: a propósito de quatro documentários". Cadernos de Antropologia e Imagem, UERJ, Rio de Janeiro, 2(3).

54. VELHO, G. 1995. "Mudanças globais e diversidade cultural: uma visão antropológica". SBPC Documenta, São Paulo, 1:25-28.

55. VELHO, G. 1995. "Introdução: O próximo e o distante". Comunicações do PPGAS, Quatro viagens: antropólogos brasileiros no exterior, Rio de Janeiro, 6:1-9.

56. VELHO, G. 1995. Quatro viagens: antropólogos brasileiros no exterior. Comunicações do PPGAS, Rio de Janeiro, 6:1-224.

57. VELHO, G. 1995. "Democracia e negociação da realidade". Tempo e Presença, $17(282): 9-10$.

58. VELHO, G. 1995. "Estilo de vida urbano e modernidade". Revista de Estudos Históricos, 16:227-234.

59. VELHO, G. 1995. "A dimensão cultural e política dos mundos das drogas". Série Estudos Contemporâneos Meio Ambiente e Sociedade, Rio de Janeiro, 1:51-59.

60. VELHO, G. 1994. "Sobre homens marginais". Anuário Antropológico, Rio de Janeiro, 1992:69-74.

61. VelHO, G. 1993. "A ciência no Brasil". Almanaque do Aluá, 1.

62. VELHO, G. 1993. "Cultura popular e sociedade de massas: uma reflexão antropológica". Piracema Revista de Arte e Cultura.

63. VELHO, G. 1992. "Project Emotion and orientation in complex societies". Sociological Theory, 10(1).

64. VELHO, G. 1992. "Ana Margarete Heye (obituário)". Boletim da ABA, 12.

65. VELHO, G. 1992. "Antropologia urbana: tradição e modernidade na cidade brasileira". Anais do Seminário de Tropicologia, Recife.

66. VELHO, G. 1991. "O grupo e seus limites". Revista USP, São Paulo.

67. VELHO, G. 1991. "Indivíduo e religião na cultura brasileira". Novos Estudos. CEBRAP.

68. VELHO, G. 1991. "Informação e Sociedade". Anais do Seminário Arte e Informação.

69. VELHO, G. 1990. "A vitória de Collor: uma análise antropológica". Novos Estudos. CEBRAP. 
70. VELHO, G. 1990. "Individualismo e juventude". Comunicação, Rio de Janeiro.

71. VELHO, G. 1990. "Colapso cultural e crise política". Série Estudos, Rio de Janeiro.

72. VELHO, G. 1989. "A atividade do antropólogo: considerações preliminares". Boletim da $A B A$.

73. VELHO, G. 1989. "Anthony Leeds (obituário)". Boletim da ABA.

74. VELHO, G. 1989. "Destino, campo de possibilidades e províncias de significado: notas sobre a violência". Comunicação, Rio de Janeiro.

75. VELHO, G. 1988. "Desenvolvimento científico e cultura: reflexões a propósito dos 170 anos do Museu Nacional". Publicações Avulsas do Museu Nacional, Rio de Janeiro.

76. VELHO, G. 1988. "Comunidade científica e políticas públicas". Ciência e Cultura (SBPC), 6.

77. VElHO, G. 1988. "Organização e Apresentação da Comunicação". Comunicação, Rio de Janeiro.

78. VELHO, G. 1988. "Antropologia e literatura: a questão da modernidade". Comunicação, Rio de Janeiro.

79. VELHO, G. 1989. "Memória, identidade e projeto". Tempo Brasileiro.

80. VELHO, G. 1987. "As vítimas preferenciais". Revista Ciência Hoje.

81. VELHO, G. 1987. "O cotidiano da violência: identidade e sobrevivência". Boletim do Museu Nacional, Rio de Janeiro, pp. 1-10.

82. VELHO, G. 1987. "O Conselho Nacional de Desenvolvimento Científico e Tecnológico em transição". Boletim da ABA, 3.

83. VELHO, G. 1986. "A grande cidade brasileira: sobre heterogeneidade e diversidades culturais". Revista do Serviço do Patrimônio Histórico e Artístico Nacional.

84. VELHO, G.; LEITE, Y. F. 1985. "Parecer da Associação Brasileira de Antropologia sobre sua participação no convênio 059/82". Revista de Antropologia (São Paulo), São Paulo, XXVII(XXVIII).

85. VELHO, G. 1985. "Ética ou éticas: perspectiva antropológica". Ética Médica, Rio de Janeiro.

86. VELHO, G. 1984. "Sistemas cognitivos e sistemas de crenças: problemas de definiÇão e comparação". Comunicação PPGAS Museu Nacional UFRJ, Rio de Janeiro.

87. VELHO, G. 1984. "Indivíduo e religião na cultura brasileira: questões preliminares". Comunicação PPGAS Museu Nacional UFRJ, Rio de Janeiro.

88. VELHO, G. 1984. "Os antropólogos brasileiros e sua Associação: discurso de encerramento de mandato". XIV Reunião da ABA, Brasília.

89. VELHO, G. 1984. "A questão indígena e o direito à diferença". Revista Ciência Hoje, 2.

90. VELHO, G. 1984. "Antropologia e patrimônio cultural". Revista do Serviço do Patrimônio Histórico e Artístico Nacional.

91. VELHO, G. 1983. "Aliança e casamento na sociedade moderna: separação e amizade em camadas médias urbanas". Boletim do Museu Nacional, Rio de Janeiro.

92. VELHO, G. 1983. "A Associação Brasileira de Antropologia e a política científica nacional". Boletim da Associação Brasileira de Antropologia.

93. VELHO, G. 1982. "Violência e relações sociais: a questão da diferença". Revista de Ciências Sociais, Fortaleza, 12/13.

94. VELHO, G.; ABRANCHES, S. 1982. "Financiamento e a regulamentação do ensino de pós-graduação da pesquisa em ciência sociais". Debates, 4.

95. VELHO, G.; CASTRO, E. B. V. 1982. "O conceito de cultura e o estudo das sociedades complexas". Cadernos Feema, Rio de Janeiro, 1. 
96. VELHO, G. 1981. "Individualismo e desmapeamento: antropologia e psicanálise". Anuário Antropológico.

97. VelHO, G. 1980. "Violência e cidadania". Dados - Revista de Ciências Sociais, Rio de Janeiro, 23.

98. VELHO, G. 1980. "Uma perspectiva antropológica do uso de drogas". Jornal Brasileiro de Psiquiatria, 29.

99. VELHO, G.; CASTRO, E. B. V. 1980. "O conceito de cultura e o estudo das sociedades complexas". Espaço Cadernos de Cultura Usu, Rio de Janeiro, 2(2):11-26.

100. VELHO, G.; 1979. HYPERLINK "http://lattes.cnpq.br/8855936483074666" \t "blank" SILVA, L. A. M. "Organização social do meio urbano". Anuário Antropológico.

101. VELHO, G. 1979. "Projeto, emoção e orientação em sociedades complexas". Boletim do Museu Nacional, Rio de Janeiro.

102. VELHO, G. 1979. "Cultura da classe média: algumas reflexões sobre a noção de projeto". Ensaios de Opinião, 10.

103. VELHO, G. 1979. "Academicismo e vida universitária". Encontros Com a Civilização Brasileira, 16.

104. VELHO, G.; CASTRO, E. B. V. 1978. "O conceito de cultura e o estudo das sociedades complexas". Artefato Jornal de Cultura do Estado do Rio de Janeiro.

105. VELHO, G. 1978. "Estilo de vida e cultura urbana". Anais do Simpósio de Planejamento Urbano e Habitacional, Rio de Janeiro.

106. VelHO, G. 1978. "Stigmatization and deviance in Copacabana". Social Proble$m s, 25(5)$.

107. VELHO, G.; CASTElAR, C.; BYINGTON, C.; KALINA, E. 1977. "A crise normal da adolescência". Revista do Centro Brasileiro de Estudos da Saúde.

108. VELHO, G. 1976. "Relações entre antropologia e psiquiatria". Revista Assoc de Psiquiatria e Psic da Infância e Adolescência, 2.

109. VELHO, G. 1976. "Favelas cariocas: o problema da marginalidade". Anuário Antropológico.

110. VELHO, G. 1976. "Accusations, family mobility and deviant behavior". Social Problems, 23(3).

111. VELHO, G.; HYPERLINK "http://lattes.cnpq.br/8855936483074666" \t "blank" SILVA, L. A. M. 1976. "Organização Social do meio urbano". Anuário Antropológico.

112. VELHO, G. 1974. "Acusações: projeto familiar e comportamento desviante". Comunicação PPGAS Museu Nacional Ufrj, Rio de Janeiro.

113. VELHO, G. 1971. "Estigma e comportamento desviante em Copacabana". América Latina, $1 / 2$.

114. VELHO, G. 1967. "Para que sociologia da arte no Brasil?". Cadernos Brasileiros, 40.

\section{Livros publicados/organizados ou edições}

1. VELHO, G. (Org.); DUARTE, L. F. D. (Org.). 2010. Juventude contemporânea: culturas, gostos e carreiras. 1. ed. Rio de Janeiro: 7Letras. v. 1. 202 p.

2. VElHO, G. (Org.); DUARTE, L. F. D. (Org.); HEILbORN, M. L. A. (Org.); BARROS, M. M. L. (Org.); RUSSO, J. A. (Org.). 2009. Gerações, família, sexualidade. 1. ed. Rio de Janeiro: 7 Letras. v. 1.96 p. 
3. VELHO, G. 2007. Rio de Janeiro: cultura, política e conflito. 1. ed. Rio de Janeiro: Jorge Zahar Editor. v. 1. 228 p.

4. VELHO, G. (Org.). 2006. Artifícios \& Artefactos. 1. ed. Rio de Janeiro: 7 Letras. v. 1. 221 p.

5. Velho, G. (Org.). 2005. Ciência e Estudos de Violência. 1. ed. Rio de Janeiro: Academia Brasileira de Ciências. 30 p.

6. VELHO, G. (Org.); KUSCHNIR, K. (Org.). Pesquisas Urbanas: desafios do trabalho antropológico. 1. ed. Rio de Janeiro: Jorge Zahar Editor, 2003. v. 1. 235 p.

7. VELHO, G. 2002. A Utopia Urbana: um estudo de antropologia social. Rio de Janeiro: Zahar Editores.

8. VELHO, G. 2002. Mudança, Crise e Violência: política e cultura no Brasil contemporâneo. Rio de Janeiro: Civilização Brasileira. 303 p.

9. VelHo, G. (Org.); KUSCHNIR, K. (Org.) . Mediação, Cultura e Política. 1. ed. Rio de Janeiro: Aeroplano. v. 1. 343 p.

10. VELHO, G. (Org.). 1999. Antropologia Urbana: cultura e sociedade no Brasil e em Portugal. Rio de Janeiro: Jorge Zahar. v. 1. 142 p.

11. VELHO, G. (Org.). 1999. Desvio e Divergência: uma crítica da patologia social. 7. ed. Rio de Janeiro: Jorge Zahar Editor. v. 1. 144 p.

12. VELHO, G. 1998. Nobres \& Anjos: um estudo de tóxicos e hierarquia. Rio de Janeiro: Ed. da FGV. v. 1.214 p.

13. VelHo, G.; AlVito, M. 1996. Cidadania e Violência. 1. ed. Rio de Janeiro: Ed. Fundação Getúlio Vargas e Editora da UFRJ. v. 1. 367 p.

14. VELHO, G. 1994. Projeto e Metamorfose: antropologia das sociedades complexas. 1. ed. Rio de Janeiro: Jorge Zahar Editor. v. 1. 137 p.

15. VELHO, G.; VELHO, O. 1992. Duas Conferências. Rio de Janeiro: Editora da UFRJ. 86 p.

16. VELHO, G. 1989. A Utopia Urbana: um estudo de antropologia social. 5. ed. Rio de Janeiro: Jorge Zahar. v. 1. 115 p.

17. VELHO, G. 1989. Subjetividade e Sociedade: uma experiência de geração. 2. ed. Rio de Janeiro: Jorge Zahar Editor.

18. VELHO, G. 1986. Subjetividade e Sociedade: uma experiência de geração. 3. ed. Rio de Janeiro: Jorge Zahar Editor. v. 1. 112 p.

19. VelHo, G. (Org.). 1983. Avaliação e Perspectivas. Brasília: SEPLAN, CNPq. v. 7.

20. VELHO, G. 1982. A Utopia Urbana: um estudo de antropologia social. Rio de Janeiro: Zahar Editores.

21. VELHO, G. 1981. Individualismo e Cultura: notas para uma antropologia da sociedade contemporânea. 1. ed. Rio de Janeiro: Zahar Editores. v. 1. 149 p.

22. Velho, G. (Org.); FIGUeIRA, S. A. (Org.). 1981. Família, Psicologia e Sociedade. 1. ed. Rio de Janeiro: Campus. v. 1.348 p.

23. VELHO, G. (Org.). 1980. O Desafio da Cidade: novas perspectivas da antropologia brasileira. 1. ed. Rio de Janeiro: Campus. v. 1. 180 p.

24. VELHO, G. 1978. A Utopia Urbana: um estudo de antropologia social. 3. ed. Rio de Janeiro: Zahar Editores.

25. VELHO, G. (Org.). 1977. Arte e Sociedade: ensaios de sociologia da arte. Rio de Janeiro: Zahar Editores. v. 1. 169 p.

26. VELHO, G. 1975. A Utopia Urbana: um estudo de antropologia social. 2. ed. Rio de Janeiro: Zahar Editores.

27. VELHO, G. 1973. A Utopia Urbana: um estudo de antropologia social. 6. ed. Rio de Janeiro: Zahar Editores. v. 1. 115 p. 
28. VelHo, G. (Org.). 1968. Sociologia da Arte. Coleção Textos Básicos de Ciências Sociais. Rio de Janeiro: Zahar Editores. v. 4.

\section{Capítulos de livros publicados}

1. VelHO, G. 2010. "Ciência Social e Cidadania". In: José Ricardo Ramalho. (Org.). Uma presença no tempo - a vida de Jether Ramalho. 1 ed. São Leopoldo: Oikos. v. 1 , p. $155-159$.

2. VELHO, G.; DUARTE, L. F. D. 2010. "Apresentação". In: Gilberto Velho; Luiz Fernando Dias Duarte. (Orgs.). Juventude contemporânea: culturas, gostos e carreiras. 1 ed. Rio de Janeiro: 7Letras. v. 1, p. 7-8.

3. VELHO, G. 2010. "Cultura subjetiva e projetos de felicidade". In: João Freire Filho (Org.). Ser feliz hoje: reflexões sobre o imperativo da felicidade. 1 ed. Rio de Janeiro: FGV. v. 1, p. 227-238.

4. VELHO, G. 2009. "Sujeito, subjetividade e projeto". In: Gilberto Velho; Luiz Fernando Dias Duarte. (orgs.). Gerações, família, sexualidade. 1 ed. Rio de Janeiro: 7 Letras. v. 1, p. 9-16.

5. VELHO, G. 2008. "O consumo de psicoativos como campo de pesquisa e de intervenção política". In: Labate, Beatriz; Caiuby [et al.] (orgs.). Drogas e Cultura: novas perspectivas. 1 ed. Salvador: EDUFBA. v. 1, p. 123-140.

6. VELHO, G. 2007. "Patrimônio, negociação e conflito". In: Manuel Ferreira Lima Filho; Cornelia Eckert; Jane Beltrão. (Orgs.). Antropologia e patrimônio cultural: diálogos e desafios contemporâneos. Blumenau: Nova Letra. p. 249-262.

7. VELHO, G. 2007. "Metrópole, cultura e conflito". In: Gilberto Velho. (Org.). Rio de Janeiro: cultura, política e conflito. 1 ed. Rio de Janeiro: Jorge Zahar Editor. v. 1, p. 1-228.

8. VELHO, G. 2007. "Mudança social, universidade e contracultura". In: Maria Isabel Mendes de Almeida; Santuza Cambraia Naves (Orgs.). "Por que não?": rupturas e continuidades da contracultura. 1 ed. Rio de Janeiro: 7 Letras. v. 1, p. 203-215.

9. VELHO, G. 2007. "O cientista social Gilberto Freyre". In: Elide Rugai bastos, Julia Peregrino e Pedro Karp (Orgs.). Gilberto Freyre, intérprete do Brasil. 1 ed. São Paulo: Museu da Língua Portuguesa. v. 1, p. 39-46.

10. VELHO, G. 2006. "A Associação Brasileira de Antropologia e seus desafios". In: Eckert, Cornelia; Godoi, Emília Pietrafesa de Godoi. (Orgs.). Homenagens: Associação Brasileira de Antropologia: 50 anos. Blumenau: Nova Letra, p. 01-405.

11. VELHO, G. 2006. Juventudes, projetos e trajetórias na sociedade. In: Almeida, Maria Isabel Mendes de; Eugenio, Fernanda (orgs.). Culturas jovens: novos mapas do afeto. Rio de Janeiro: Jorge Zahar, p. 1-236.

12. VELHO, G. 2006. "Autoria e criação artística". In: Gilda Santos; Gilberto Velho. (Orgs.). Artifícios \& Artefactos. Rio de Janeiro: 7 Letras. p. 01-221.

13. VELHO, G. 2005. "O observador participante". In: William Foote Whyte (org.), Sociedade de Esquina: a estrutura social de uma área urbana pobre e degradada. 1 ed. Rio de Janeiro: Zahar Editores, p. 9-13.

14. VELHO, G. 2005. "Reflexões sobre a Escola de Chicago". In: Licia do Prado Valladares (Org.). A Escola de Chicago: Impacto de uma tradição no Brasil e na França. Belo Horizonte/ Rio de Janeiro: UFMG/ IUPERJ, p. 53-68. 
15. VELHO, G. 2005. "Evaristo: Lições de Humanismo". In: Elina Gonçaves da Fonte Peçanha; Regina Lúcia de Moraes Morel; Gláucia Villas Boas (Orgs.). Evaristo de Moraes Filho, um intelectual humanista. Rio de Janeiro: Topbooks, v. 1, p. 309-318.

16. VELHO, G. 2004. "Becker, Goffman e a Antropologia no Brasil". In: Édison Gastaldo (Org.). Erving Goffman: desbravador do cotidiano. 1 ed. Porto Alegre: Tomo Editorial, v. 1, p. 37-47.

17. VELHO, G. 2004. "Avaliação da pesquisa e da pós-graduação". In: H. Moysés Nussenzveig (Org.), Repensando a universidade. 1 ed. Rio de Janeiro: Editora UFRJ/Copea, v. 1, p. 75-117.

18. VELHO, G. 2004. "Prestigio y ascenso social: los límites del individualismo en la sociedad brasileña". In: Alejandro Grimson, Gustavo Lins Ribeiro, Pablo Semán (Org.), La antropologia brasileña contemporánea: contribuiciones para un diálogo latinoamericano. 1 ed. Buenos Aires: Prometeo Libros, v. 1, p. 391-408.

19. VELHO, G. 2004. "A contribuição de Clifford Geertz". In: Clifford Geertz (Org.). Observando o Islã: o desenvolvimento religioso no Marrocos e na Indonésia. Rio de Janeiro: Jorge Zahar, v. 1, p. 7-10.

20. VELHO, G. 2004. "Um trabalho pioneiro". In: Carmen Dora Guimarães (Org.). O homossexual visto por entendidos. 1 ed. Rio de Janeiro: Garamond, v. 1, p. 13-16.

21. VELHO, G. 2003. "Dimensões da cultura na sociedade moderno-contemporânea". In: vários. (Org.). Cruzamento de saberes. Aprendizagens sustentáveis. 1 ed. Lisboa: Fundação Calouste Gulbenkian.

22. VELHO, G. 2003. "Continuidade e inovações na antropologia portuguesa: cidade e diversidade". In: Cordeiro, G. I.; Baptista, L. V.; Costa, A. F. da (Orgs.). Etnografias Urbanas. Oeiras: Celta.

23. VELHO, G. 2003. "O desafio da proximidade". In: VELHO, G.; Kuschnir, K. (Orgs.). Pesquisas Urbanas: desafios do trabalho antropológico. 1 ed. Rio de Janeiro: Jorge Zahar Editor. v. 1, p. 11-19.

24. VELHO, G. 2003. "O lugar da interdisciplinariedade". In: Celia Camargo et alli (org.), CPDOC 30 anos. Rio de Janeiro: FGV.

25. VELHO, G. 2002. "Antropologia e cidade". In: Lúcia Lippi Oliveira (Org.). Cidade, História e Desafios. Rio de Janeiro: Ed. da Fundação Getulio Vargas, p. 36-41.

26. VELHO, G. 2002. "O significado da obra de Gilberto Freyre para a Antropologia Contemporânea". In: Fundação Gilberto Freyre. (Org.). Seminário Internacional Novo Mundo nos Trópicos. Recife: Fundação Gilberto Freyre, p. 115-116.

27. VELHO, G. 2002. "The challenge of violence". In: Vários (Org.). Dilemmas and Challenges. 1 ed. São Paulo: Edusp, p. 155-161.

28. VELHO, G. 2001. "Biografia, trajetória e mediação". In: Velho, Gilberto; Kuschnir, Karina (Org.). Mediação, Cultura e Política. Rio de Janeiro: Aeroplano, p. 13-28.

29. VELHO, G. 2001. "Erinnerung, Kultur und Gesellschaft". In: Leibing, Annette; Benninghoff-Lühl, Sibylle (Org.). Brasilien - Land ohne Gedächtnis? 1 ed. Hamburg: Universitätspublikationen, p. 23-24.

30. VELHO, G. 2001. "Prefácio: memória, cultura e sociedade". In: Leibing, Annette; Benninghoff-Lühl, Sibylle (Org.). Devorando o tempo: Brasil, o país sem memória. 1 ed. São Paulo: Mandarim.

31. VelHo, G. 2000. "Código de Honra". In: A. E. W. Mason. (Org.). As Quatro Penas Brancas - Uma Aventura Heróica. Rio de Janeiro: Lacerda Ed., p. 5-8. 
32. VELHO, G.; KUSCHNIR, K. 2000. "Mediação e Metamorfose". In: Kuschnir, Karina. (Org.). Eleições e Representação no Rio de Janeiro. Rio de Janeiro: Relume Dumará, p. 81-89.

33. VelHO, G. 1999. "Os mundos de Copacabana". In: Gilberto Velho (Org.). Antropologia Urbana: cultura e sociedade no Brasil e em Portugal. 1 ed. Rio de Janeiro: Jorge Zahar, p. 11-23.

34. VELHO, G. 1999. "Sociedades Moderno-contemporâneas: uma perspectiva antropológica". In: H. Moysés Nussenzveig (Org.). Complexidade e Caos. 1 ed. Rio de Janeiro: COPEA/UFRJ, p. 134-138.

35. VELHO, G. 1999. "Anselm Strauss: indivíduo e vida social". In: Anselm Strauss. (Org.). Espelhos e Máscaras. São Paulo: Edusp, p. 11-19.

36. VELHO, G. 1999. "Universidade e pluralismo sociocultural". In: Heidrun Krieger Olinto; Karl Erik Schollhammer (Orgs.). Novas Epistemologias: desafios para a universidade do futuro. Rio de Janeiro: Nau / PUC - Departamento de Letras, p. 125-132.

37. VELHO, G. 1998. "Unidade e Fragmentação em Sociedades Complexas". In: Jessé Souza; Berthold Öelze (Orgs.). Simmel e a Modernidade. 1 ed. Brasília: UnB, p. 255-274.

38. VELHO, G. 1997. "Drogas e Construção Social da Realidade". In: Batista, Marcos; Inem, Clara (Orgs.). Toxicomania: abordagem multidisciplinar. Rio de Janeiro: Nepad-Uerj/Sette Letras, p. 9-13.

39. VELHO, G. 1997. "Drogas, Níveis de Realidade e Diversidade Cultural". In: Ribeiro, Maurides de Melo; Seibel, Sérgio Dario (Orgs.). Drogas: hegemonia do cinismo. 1 ed. São Paulo: Fundação Memorial da América Latina, v. 1, p. 61-69.

40. VELHO, G. 1996. "Estado, mercado e democracia no contexto de uma nova ordem internacional: uma visão antropológica". In: Ana Nunes de Almeida (Org.). Dinâmicas Multiculturais: novas faces, outros olhares. 1 ed. Lisboa, Portugal: Instituto de Ciências Sociais da Universidade de Lisboa, v. 1, p. 77-80.

41. VELHO, G. 1996. "Depoimento". In: Lucia Blanc (Org.). Um Rio de Culturas: vozes da cidade. 1 ed. Rio de Janeiro: Secretaria Municipal de Cultura, v. 1, p. 43-47.

42. VELHO, G. . Violência, reciprocidade e desigualdade: uma perspectiva antropológica. In: VELHO, Gilberto; ALVITO, Marcos. (Org.). Cidadania e Violência. Rio de Janeiro: Fundação Getúlio Vargas/UFRJ, 1996, v. 1, p. 10-24.

43. VELHO, G. 1995. "A democracia não prescinde da cidadania cultural". In: Nilton Santos; Roberto Ribeiro (Orgs.). O Encontro: um olhar sobre a cultura, o cidadão e a empresa. Rio de Janeiro: Ed. Senai/Dpto, v. 1, p. 49-60.

44. VELHO, G. 1994. "Global changes and cultural diversity: an anthropological view". In: Morales, M. C. Patrícia (Org.). Indigenous Peoples, Human Rights and Global Interdependence. 1 ed. Tiubure, The Netherlands: International Center for Human and Public Affairs, v. 1.

45. VELHO, G. 1994. "A dimensão cultural e política do mundo das drogas". In: Zaluar, Alba (Org.). Drogas e Cidadania. 1 ed. São Paulo: Brasiliense, v. 1.

46. VElHO, G. 1994. "Sociedade e Cultura". In: Parente, José Inácio; Monte-Mór, Patrícia (Orgs.). Rio de Janeiro: Retratos da Cidade. 1 ed. Rio de Janeiro: Interior Produções/Banco do Brasil, v. 1.

47. VelHO, G. 1993. "A experiência do Programa de Pós-Graduação em Antropologia Social/Departamento de Antropologia do Museu Nacional/UFRJ". In: Sérgio Miceli (Org.). A Fundação Ford no Brasil. São Paulo: Saraiva/FAPESP. 
48. VELHO, G. 1993. "Dimensão cultural e política do mundo das drogas". In: Clara Lucia Inem; Gilberta Acselrad (Orgs.). Drogas: uma visão contemporânea. Rio de Janeiro: Imago.

49. VELHO, G. 1991. "Ciências sociais e humanismo". In: Helena Bomeny; Patrícia Birman (Orgs.). As Assim Chamadas Ciências Sociais: formação do cientista social no Brasil. Rio de Janeiro: UERJ/Relume Dumará.

50. VELHO, G. 1988. "Destino e projeto: uma visão antropológica". In: Eduardo Prado (Org.). Destino. Rio de Janeiro: Terceira Margem.

51. VELHO, G. 1987. "Família e subjetividade". In: Angela Mandes de Almeida (Org.), Pensando a Família no Brasil. Rio de Janeiro: Espaço e Tempo/Ed. da UFRJ.

52. VELHO, G. 1986. "Antropologia Urbana". In: Editora da Fundação Getulio Vargas (Org.). Dicionário de Ciências Sociais. Rio de Janeiro: Editora da Fundação Getulio Vargas, p. 68-69.

53. VELHO, G. 1985. "A busca de coerência: coexistência e contradições entre códigos em camadas médias urbanas". In: Sérvulo Figueira (org.), Cultura da Psicanálise no Brasil: psicanálise e psicologia na sociedade contemporânea. São Paulo: Brasiliense.

54. VELHO, G. 1985. "O consumo da cannabis e suas representações culturais". In: Maria Sabina (Org.). Maconha em Debate. São Paulo: Brasiliense.

55. VELHO, G. 1985. "O cotidiano como objeto de reflexão na obra de Gilberto Freire". In: FUNARTE/Insituto Nacional do Folclore (Org.). Casa Grande \& Senzala 50 anos depois: um encontro com Gilberto Freire. Rio de Janeiro: FUNARTE/Instituto Nacional do Folclore, 1985, v. , p. -.

56. VELHO, G. 1985. "Duas categorias de acusação na cultura brasileira contemporânea". In: Sérvulo Figueira (Org.). Sociedade e Doença Mental. Rio de Janeiro: Campus.

57. VELHO, G. 1985. “Conformación de la cultura moderna de classe media en Brasil: una perspectiva antropológica". In: Richard Morse; Jorge Enrique Hardoy (Org.), Cultura Urbana Latino-americana. Buenos Aires: CLACSO.

58. VELHO, G. 1983. "Introdução de Ciências Humanas e Sociais". In: VELHO, G. (Org.), Avaliação e Perspectivas. Brasília: SEPLAN, CNPq, v. 7.

59. VELHO, G. 1982. "Literatura e desvio: questões para a antropologia". In: Editora Brasiliense (Org.). Caminhos Cruzados. São Paulo: Brasiliense.

60. VELHO, G. 1982. "An anthropologist's point of view". In: Masao Yamaguchi (ed). Dialogues. Tóquio: Iw Anami Shoteün Publishers.

61. VELHO, G. 1981. "Parentesco, individualismo e acusações". In: Gilberto Velho; Sérvulo Figueira (Orgs.). Família, Psicologia e Sociedade. Rio de Janeiro: Campus.

62. VELHO, G. 1980. "Projeto, emoção e orientação em sociedades complexas". In: Sérvulo A. Figueira (Org.). Psicanálise e Ciências Sociais. 1 ed. Rio de Janeiro: Francisco Alves.

63. VELHO, G. 1980. "O antropólogo pesquisando em sua cidade: sobre conhecimento e heresia". In: Gilberto Velho (Org.). O Desafio da Cidade: novas perspectivas da antropologia brasileira. Rio de Janeiro: Campus.

64. VELHO, G. 1978. "Vanguarda e desvio". In: Gilberto Velho (Org.). Arte e Sociedade: ensaios de sociologia da arte. Rio de Janeiro: Zahar Editores.

65. VelHo, G. 1978. "Observando o familiar". In: Edson Nunes (Org.). Aventura Sociológica. Rio de Janeiro: Zahar Editores, p. 36-46. 
66. VELHO, G. 1978. "Duas categorias de acusação na cultura brasileira contemporânea". In: Sérvulo Figueira (Org.). Sociedade e Doença Mental. Rio de Janeiro: Campus.

67. VELHO, G. 1977. "Cotidiano e política num prédio de conjugados". In: José Augusto Guilhon de Albuquerque (org.). Classes Médias e Política no Brasil. Rio de Janeiro: Paz e Terra.

68. VELHO, G. 1974. "O estudo do comportamento desviante: a contribuição da antropologia social". In: Gilberto Velho (org.). Desvio e Divergência: uma crítica da patologia social. Rio de Janeiro: Zahar Editores.

69. VELHO, G. 1974. "Estigma e comportamento desviante em Copacabana". In: Gilberto Velho (Org.). Desvio e Divergência: uma crítica da patologia social. Rio de Janeiro: Zahar editores. 


\section{Anexo 2 - Listagem de dissertações e teses orientadas por Gilberto Velho até 2012}

\section{Mestrado, orientação, no PPGAS/Museu Nacional/UFRJ}

"Fronteiras do Silêncio: um estudo de desvio e ritualização". Rosine Jozef Perelberg. Defendida em 20/9/76.

"Anões Contra Gigantes: o movimento de defesa da ecologia no bairro da Gávea, Rio de Janeiro". Márcia Bandeira de Mello Leite Nunes. Defendida em 3/8/77.

"O Homossexual Visto por Entendidos". Carmem Dora Guimarães. Defendida em 10/11/77.

"Mata Machado: um estudo sobre moradia urbana". Ana Margarete Heye. Defendida em 13/6/79.

"Três Movimentos Sociais Urbanos no Rio de Janeiro". Carlos Nelson Ferreira dos Santos. Defendida em 21/6/79.

"Dentro de um Ponto Riscado: estudo de um centro espírita na Zona Norte do Rio de Janeiro". Zélia Milanez de Lóssio Seiblitz. Defendida em 28/12/79.

"Retrato de Época: um estudo de produção cultural nos anos 70". Carlos Alberto Messeder Pereira. Defendida em 13/2/80.

"De Pivete à Criança: um estudo antropológico numa instituição de menores". Silvana Miceli de Araújo. Defendida em 7/3/80.

"Testemunho de Vida: um estudo antropológico de mulheres na velhice". Myriam Moraes Lins de Barros. Defendida em 14/3/80.

"Raça, Sangue e Luta: identidade e parentesco em uma cidade do interior". Ovídio de Abreu Filho. Defendida em 16/4/80.

"Os Gênios da Pelota: um estudo do futebol como profissão". Ricardo Augusto Benzaquem de Araújo. Defendida em 28/4/80.

"Balão no Céu, Alegria na Terra: um estudo sobre representação e organização social dos baloeiros". Sandra Maria Corrêa de Sá Carneiro. Defendida em 17/11/82.

"O Caso da Pomba-Gira: reflexões sobre crime, possessão e identidade feminina". Márcia de Vasconcelos Contins Gonçalves. Defendida em 16/11/83.

"Garotas de Programa: um estudo sobre a prostituição e identidade social". Maria Dulce Barcellos Gaspar de Oliveira. Defendida em 16/3/84.

"Conversa de Portão: Juventude e Sociabilidade em um Subúrbio Carioca". Maria Luiza de Amorim Heilborn. Defendida em 4/5/84.

"O Fenômeno Psicanálise: uma abordagem interdisciplinar". Ronaldo da Costa Formiga. Defendida em 29/3/85.

"O Baile Funk: festas e estilos de vida metropolitanos". Hermano Paes Vianna Júnior. Defendida em 18/12/87.

"Astrologia: um estudo de antropologia social". Luis Rodolfo da Paixão Vilhena. Defendida em 21/3/88.

“'O Belo Sexo': imprensa e identidade feminina no Rio de Janeiro em fins do século XIX e início do século XX". Maria Fernanda Baptista Bicalho. Defendida em 8/4/88. 
"Objeto não Identificado: a trajetória de Caetano Veloso". Santuza Cambraia Naves Ribeiro. Defendida em 29/4/88.

“Nos Embalos de Sábado à Noite: juventude e sociabilidade em camadas médias cariocas". Cláudia Barcellos Rezende. Defendida em 30/4/89.

"Moralidade e Sociabilidade: contribuição a uma antropologia da juventude". Silvia Regina de Almeida Fiuza. Defendida em 28/6/89.

"O Espírito Militar: um estudo de antropologia social na Academia Militar das Agulhas Negras". Celso Corrêa Pinto de Castro. Defendida em 15/9/89.

"Teatro e Contracultura: um estudo de antropologia social". Maria Claudia Pereira Coelho. Defendida em 15/12/89.

"O Mundo das Mulheres: uma investigação sobre o movimento feminista no Rio de Janeiro". Carla Costa Teixeira. Defendida em 8/3/91.

"O Mundo dos Jornalistas: um estudo antropológico sobre identidade e carreira em camadas médias". Isabel Siqueira Travancas. Defendida em 31/10/91.

"A Boa Mesa Mineira: um estudo de cozinha e identidade". Rogéria Campos de Almeida Dutra. Defendida em 12/12/91.

"Aids e a Imprensa: um estudo de antropologia social". Jane Lucia Faislon Galvão. Defendida em 24/3/92.

"Hoje é o Dia do Santo Reis: um estudo de cultura popular no Rio de Janeiro". Patrícia Monte-Mór de Morais. Defendida em 27/3/92.

"Vamos Fazer Bagunça!? Por uma antropologia das paixões". Maria Cristina da Costa Lyra. Defendida em 30/3/92.

"Telenovela e Texto Cultural: análise antropológica de um gênero em construção". Mônica Roque Coutinho. Defendida em 12/2/1993.

"Política e Mediação Cultural: um estudo na Câmara Municipal do Rio de Janeiro". Karina Kuschnir. Defendida em 11/11/93.

"MASP: um museu e seu público". Andréa Cláudia Miguel Marques Barbosa. Defendida em 7/3/94.

"Arte e Educação: um estudo de antropologia social na Escola de Artes Visuais do Parque Lage". Marcia Lahtermaher. Defendida em 12/9/94.

"O Banquete de Trimalcião: ethos de corte num setor da elite brasileira". Carlos Eduardo de Castro Leal. Defendida em 17/8/95.

“Umbanda e Assistencialismo: um estudo sobre representação e identidade em uma instituição da Baixada Fluminense". Ana Lucia Enne. Defendida em 18/8/95.

"Jogo, Praça Pública e Sociabilidade Masculina". Sonia Duarte Travassos. Defendida em 1/9/95.

"Distante, não obstante Próximos". Lucia Sheila Blanc. Defendida em 6/2/96.

"Mulheres, Militância e Memória". Elizabeth Fernandes Xavier Ferreira. Defendida em 15/2/96.

"Vivendo na Cachimba: considerações sobre participação política num bairro de Curitiba". Nilton Silva dos Santos. Defendida em 25/2/97.

"As Obrigações do Poder: relações pessoais e vida pública na correspondência de Filinto Müller". Luciana Quillet Heymann. Defendida em 11/3/97.

"Biografias e Heróis no Imaginário Nacionalista Moçambicano". Cristiano Benedito Alves Matsinhe. Defendida em 26/8/97. 
"Jovens Colegas: um estudo de carreira e socialização no Instituto Rio Branco". Cristina Patriota de Moura. Defendida em 21/1/99.

"Vida, Glória e Morte de Rui Barbosa: a construção de um herói nacional". João Felipe Ferreira Gonçalves. Defendida em 25/8/99.

"Os segredos da imortalidade: uma etnografia da Academia Brasileira de Letras". Valéria Torres da Costa e Silva. Defendida em 23/9/99.

"Política e vida associativa em um bairro carioca". Alessandra Siqueira Barreto. Defendida em 17/1/01.

"Na Batida da Zabumba: uma análise antropológica do forró universitário". Roberta Lana de Alencastre Ceva. Defendida em 18/6/01.

"Bricoleur de rua: um estudo antropológico da cultura hip-hop carioca". Sandra Regina Soares da Costa. Defendida em 18/1/02.

"Negros homossexuais: raça e hierarquia no Brasil e na Colômbia". Maria Elvira Diáz Benitez. Defendida em 11/2/05.

"Entre a "pista" e o "camelódromo". O cotidiano dos camelôs no Centro do Rio de Janeiro". Patrícia Delgado Mafra. Defendida em 18/2/05.

"Nasci para sonhar e cantar: gênero, projeto e mediação na trajetória de Dona Ivone Lara". Mila Burns. Defendida em 20/02/06.

"Em busca das namoradas de fé". Liane Maria Braga da Silveira. Defendida em 22/01/07.

"No olho da rua: a etnografia urbana de João do Rio". Julia Galli O’ Donnell. Defendida em 26/01/07.

"Mulheres de militares: família, sociabilidade e controle social". Fernanda Chinelli Machado da Silva. Defendida em 22/02/08.

"Trajetórias, acusações e sociabilidade: uma etnografia em um centro de convivência para pacientes psiquiátricos". Sílvia Monnerat. Defendida em 26/01/09.

“'Só há solidão porque vivemos com os outros...': um estudo sobre as vivências de solidão e sociabilidade entre mulheres que vivem sós no Rio de Janeiro". Isis Ribeiro Martins. Defendida em 24/02/2010.

"Tom Jobim: trajetória, carreira e mediação sócio-culturais". Caio Gonçalves Dias. Defendida em 25/02/2010.

"Gênero musical, mercado e cultura de gosto". Raquel Sant'ana da Silva. Defendida em 14/02/2012.

\section{Mestrado, orientação, em outras instituições}

"Cemitério dos Vivos". Julita Lemgruber. Instituto Universitário de Pesquisas do Rio de Janeiro (IUPERJ). Defendida em 5/9/79.

"Arquitetura de Espaços Urbanos como Expressão de Processos de Organização Social". Ferdinando de Moura Rodrigues. Programa de Planejamento Urbano e Regional da COPPE/UFRJ. Defendida em 15/9/80.

"A Dialética do Estranhamento: a reconstrução da identidade social de mulheres separadas em Porto Alegre". Ana Luiza Carvalho da Rocha. Curso de Pós-Graduação em Antropologia Social da Universidade Federal do Rio Grande do Sul (UFRGS). Defendida em 9/10/85. 


\section{Mestrado, Co-orientação, em outras instituições}

"Reis e Rainhas no Desterro". Regina Maria Erdmann. Departamento de Ciências Sociais da Universidade Federal de Santa Catarina (UFSC). Defendida em $17 / 2 / 81$.

\section{Doutorado, orientação, no PPGAS/Museu Nacional/UFRJ}

"Da Vida Nervosa: pessoa e modernidade entre as classes trabalhadoras". Luiz Fernando Dias Duarte. Defendida em 25/2/85.

"Avós: Autoridade e Afeto. Um estudo de família em camadas médias". Myriam Moraes Lins de Barros. Defendida em 16/6/86.

“Nome de Família: maternidade fora do casamento e o princípio da filiação patrilinear". Tania Dauster Magalhães e Silva. Defendida em 3/8/87.

"Sobre o Casal Grávido: incursão em um universo ético". Tania Raquel Salem. Defendida em 14/9/87.

"Os Filhos do Coração: um estudo antropológico da adoção em camadas médias brasileiras". Maria Cecília Solheid da Costa. Defendida em 17/10/88.

"O Corpo Contra a Palavra: as terapias corporais no campo psicológico dos anos 80". Jane Araújo Russo. Defendida em 16/8/91.

"Dois é par: conjugalidade, gênero e identidade". Maria Luiza de Amorim Heilborn. Defendida em 30/7/92.

"A Descoberta do Samba: música popular e identidade nacional". Hermano Paes Vianna Jr. Defendida em 27/1/94.

"Os Militares e a República". Celso Corrêa Pinto de Castro. Defendida em 23/6/95.

"Missão e Projeto: o movimento folclórico brasileiro (1947-1964)". Luis Rodolfo da Paixão Vilhena. Defendida em 29/6/95.

"Os Mandarins Milagrosos: ideologia da arte, modernismo e cultura popular". Elizabeth Travassos Lins. Defendida em 17/12/96.

“Trocas, Facções e Partidos: um estudo da vida política em Araruama-RJ". Ana Claudia Coutinho Viegas. Defendida em 14/8/97.

"O Vencedor de Demandas: a trajetória e obra de um artista popular". Letícia Costa Rodrigues Vianna. Defendida em 17/12/98.

"Política e Sociabilidade: um estudo de antropologia social". Karina Kuschnir. Defendida em 18/12/98.

"Capoeira - Difusão \& Metamorfose culturais entre Brasil e EUA". Sônia Duarte Travassos. Defendida em 1/9/00.

"Santos e canalhas. Uma análise antropológica da obra de Nelson Rodrigues". Adriana Facina Amaral. Defendida em 18/12/02.

"A dama e o cavalheiro: um estudo antropológico sobre envelhecimento, gênero e sociabilidade". Andréa Moraes Alves. Defendida em 14/3/03.

"Ilhas Urbanas: Novas Visões do Paraíso. Uma discussão etnográfica dos condomínios horizontais". Cristina Patriota de Moura. Defendida em 27/10/03.

"Sociabilidade e conflito no morro e na rua: etnografia de um Centro Comunitário em Vila Isabel/RJ". Fernanda Delvalhas Piccolo. Defendida em 06/01/06. 
"Universo sonoro popular: um estudo da carreira de músico nas camadas populares." Sandra Regina Soares da Costa. Defendida em 22/02/06.

"Cartografia política: as faces e fases da política na Baixada Fluminense". Alessandra Siqueira Barreto. Defendida em 24/07/06.

"Heavy metal no Rio de Janeiro e dessacralização de símbolos religiosos: a música do demônio na cidade de São Sebastião das Terras de Vera Cruz". Pedro Alvim Leite Lopes. Defendida em 14/08/06.

"Individualismo, família e projeto: negociando identidades em casais formados por judeus e não judeus". Marcelo Gruman. Defendida em 11/12/06.

"Família e redes sociais: um estudo sobre práticas e estilos alimentares no meio urbano". Rogéria Campos de Almeida Dutra. Defendida em 26/02/07.

"O Arco das Lapas: um estudo de antropologia urbana". Ana Carmen Amorim Jara Casco. Defendida em 10/09/07.

"Na lan house, "porque jogar sozinho não tem graça": estudo das redes sociais juvenis on- e off line". Vanessa Andrade Pereira. Defendida em 26/02/08.

"Nas redes do sexo: bastidores e cenários do pornô brasileiro". Maria Elvira Diaz Benitez. Defendida em 27/02/2009.

"Construindo identidades: um estudo etnográfico sobre manipulação da aparência em salões de beleza na cidade do Rio de Janeiro". Patrícia Gino Bouzón. Defendida em 10/02/2010.

"Um Rio Atlântico: culturas urbanas e estilos de vida na invenção de Copacabana". Julia Galli O`Donnel. Defendida em 21/01/11.

"'Como se fosse da família': a relação (in)tensa entre mães e babás". Liane Maria Braga da Silveira. Defendida em 24/02/2011.

“'O Rio que passa por Arthur Azevedo': cotidiano e vida urbana na Capital Federal na alvorada do século XX". Tatiana Braga Oliveira. Defendida em 29/06/2011.

\section{Doutorado, co-orientação, em outras instituições}

"Policiamentos, cidades e citadinos. Para uma etnografia da segurança." Susana Durão. Instituto Superior de Ciências do Trabalho e da Empresa. (ISCTE). Lisboa, Portugal. Defendida em 14/11/08. 